Cómo citar este trabajo: Arias-García, J. (2019). Propuesta metodológica para la identificación, caracterización y cualificación de los paisajes: la cuenca endorreica de Padul (Andalucía) como caso de estudio. Boletín de la Asociación de Geógrafos Españoles, 80, 2604, 1-43. http://dx.doi.org/10.21138/bage.2604

\title{
Propuesta metodológica para la identificación, caracterización y cualificación de los paisajes: la cuenca endorreica de Padul (Andalucía) como caso de estudio
}

\author{
Methodological proposal for the classification, \\ characterization and qualification of landscapes: \\ the endorheic basin of Padul (Andalusia) as a case study

\section{Jonatan Arias-García} \\ jariasgarcia@ugr.es \\ Departamento Análisis Geográfico Regional y Geografía Física \\ Universidad de Granada (España)
}

\section{Resumen}

Se presenta una propuesta metodológica que permita identificar, caracterizar y cualificar los paisajes en las cuencas hidrográficas de tipo endorreico y sus humedales asociados. La metodología, que considera la posibilidad de implementar el Convenio Europeo del Paisaje, consta de dos etapas: identificación y caracterización; y valoración y propuestas. La primera etapa consiste en la delimitación de unidades de paisaje y su clasificación en Tipos y Áreas de acuerdo con la metodología LCA (Landscape Character Assessment); caracterización e integración multiescalar. La segunda etapa tiene como objetivo establecer una valoración y significación de estos paisajes a partir de su cualificación y establecimiento de objetivos de calidad paisajística. El método propuesto ha permitido establecer una perspectiva transversal del análisis paisajístico al desarrollar: un ejercicio descriptivo-analítico de los fundamentos naturales del paisaje, procesos históricosocioeconómicos y escénico-visuales; un ejercicio de diagnóstico atendiendo a la transformación de 
las bases naturales del paisaje (geosistemas o unidades ecogeográficas originales); y un ejercicio propositivo que contempla la valoración del paisaje y sus posibilidades de actuación.

Palabras clave: metodología; Áreas y Tipos de paisaje; LCA; Convenio Europeo del Paisaje.

\begin{abstract}
This paper presents a methodological proposal to classify, characterize and qualify landscapes in the endorheic basins and their associated wetlands. The methodology, which considers the possibility of implementing the European Landscape Convention, contains two stages: identification and characterization; and assessment and proposals. The first stage consists of the delimitation of landscape units and their classification in Types and Areas according to the methodology LCA (Landscape Character Assessment); characterization and multi-scalar integration. The second stage aims to establish an assessment and meaning of these landscapes based on their qualification and establishment of landscape quality objectives. The proposed methodology allowed us to establish a transversal perspective of the landscape analysis by carrying out: a descriptive-analytical exercise of the natural features of the landscape, historical-socioeconomic and scenic-visual processes; a diagnostic exercise based on the transformation of the natural bases of the landscape (geosystems or original ecogeographic units); and a forward-looking exercise, that contemplates the assessment of the landscape and its possibilities of action.
\end{abstract}

Key words: methodology; Areas and Types of landscape; LCA; European Landscape Convention.

\title{
1 Introducción
}

Las cuencas hidrográficas de tipo endorreico se caracterizan por poseer un sistema de drenaje interno en el que las aguas confluyen o desembocan en su nivel de base. El agua puede desaparecer por infiltración y/o evaporación, o bien estancarse y conformar humedales cuyo origen, tipo, dimensión, dinámica y estacionalidad será variable en función de las características mesológicas de cada cuenca (Laity, 2008).

Los espacios endorreicos representan el $25 \%$ de la superficie terrestre y concentran aproximadamente el $6 \%$ de la población mundial (Varis \& Kummu, 2012). Se localizan principalmente en las regiones áridas y semiáridas intracontinentales del planeta: cuenca del Mar de Aral, entre Kazajistán y Uzbekistán; Mar Muerto, entre Israel, Palestina y Jordania; Lago Eyre en Australia; lagunas de Gallocanta y Fuente de Piedra en España, etc.

Este tipo de cuencas y especialmente sus humedales asociados han supuesto a lo largo de la historia un importante atractivo para la sociedad por los diversos recursos que ofrecían (caza, pesca, extracción de sal, etc.). Recientemente, factores como la sobreexplotación agrícola o el aumento de la irrigación han contribuido progresivamente al agotamiento de estas reservas y la 
consecuente transformación de sus paisajes (Hostetler, 1995; Lemly, Kingsford \& Thompson, 2000; Joly, 2006; Elmore et al., 2008; Varis \& Kummu, 2012; Wurtsbaugh et al., 2017). Por ello, la singularidad y fragilidad de estos ámbitos como ecosistemas y paisajes determinan un notable interés para su análisis y diagnóstico.

Hasta el momento, las investigaciones relacionadas con las cuencas endorreicas y los humedales asociados a ellas se han abordado desde una perspectiva sectorial bajo una óptica estrictamente climática, hidrológica y geomorfológica en la que prevalece el análisis de la relación entre la aridez y el endorreísmo a distintas escalas espaciales, cuando no se han centrado exclusivamente en el humedal como ecosistema (Arias-García \& Gómez-Zotano, 2015; Arias-García, Gómez-Zotano \& Delgado-Peña, 2017). En este sentido, son numerosas las investigaciones que, con un enfoque climático e hidrogeomorfológico, han tenido como objeto de estudio los diferentes grandes sistemas endorreicos del planeta: las cuencas endorreicas de Asia Central (Varis \& Kummu, 2012; Yapiyev et al., 2017); el Gran Lago Salado de Utah en Norteamérica (Belovsky et al., 2011; Huybers, Rupper \& Roe, 2016); el Mar Caspio (Dumont, 1998); el Lago Titicaca del Altiplano andino (Delclaux, Coudrain \& Condom, 2007); el sistema TDPS (Sistema endorreico Titicaca-DesaguaderoPoopó-Salar de Coipasa) en la meseta del Collado (Sudámerica) (Canedo, Pillco Zolá \& Berndtsson, 2016); el Lago Chad, situado en la frontera entre Chad, Níger, Nigeria y Camerún (Lemoalle et al., 2012); o el australiano Lago Eyre (Habeck-Fardy \& Nanson, 2014).

No obstante, la carencia de aportaciones vinculadas al paisaje en este tipo de espacios conlleva consecuentemente a la inexistencia de una metodología sólida que permita abordar su análisis a escala de detalle. Sin embargo, a partir del año 2000, Europa experimenta un auge en cuanto a demandas procedimentales y metodológicas derivadas del Convenio Europeo del Paisaje (CEP). Este Convenio pretende, entre otros aspectos, impulsar un mayor esfuerzo por parte de los Estados firmantes para llevar a cabo la protección, gestión y ordenación de los paisajes; cuestión que previamente implica la identificación, caracterización y cualificación de los mismos. Por tanto, se requiere de una metodología que atienda a criterios ambientales, históricos, socioculturales y escénico-visuales bajo un enfoque holístico, máxime para este tipo de espacios que, por su carácter cerrado o autocontenido, adquieren una gran fragilidad frente a las intervenciones antrópicas especialmente en aquellos donde se han desarrollado humedales de diverso tipo que en determinados casos se encuentran profusamente degradados-, convirtiéndose así en enclaves de interés para implementar una metodología que permiła la identificación y caracterización de los paisajes y su consecuente valoración y/o cualificación.

En este marco, el objetivo del presente trabajo es generar una propuesta metodológica que permita la implementación del CEP en los ámbitos territoriales asociados a cuencas endorreicas. Para la consecución de este objetivo se propone un procedimiento metodológico fundamentado en la guía para la estimación del carácter paisajístico o método LCA: "Landscape Character Assessment: 
Guidance for England Scotland", desarrollada en 2002 por la Countryside Agency and Scottish Natural Heritage (Reino Unido) y cuya utilidad ha sido constatada en numerosos trabajos que han tenido como objetivo la identificación, caracterización y cualificación de los paisajes a distintas escalas espaciales (ej. Gómez Zotano \& Riesco Chueca, 2010; Butler \& Åkerskog, 2014; Barlett et al., 2017; Li \& Zhang, 2017; Trop, 2017). Aunque esta guía constituye la base del método propuesto, se han incorporado determinadas modificaciones con la finalidad de adaptarla a los principios derivados del CEP, concretamente a los apartados C (Identificación y Calificación) y D (Objetivos de Calidad Paisajística) del Convenio (Art. 6. Medidas particulares).

La metodología propuesta presenta un carácter sistémico (comprende las estructuras territoriales que se derivan del doble entramado del subsistema natural y sociocultural), genético (tiene como objetivo conocer cómo se ha llegado a la configuración actual de los paisajes), interescalar (permite adecuarse a diferentes escalas espaciales) e iterativo (expresa una acción que se compone de acciones repetidas; en este caso una clasificación en Áreas y Tipos paisajísticos).

Para la implementación de la propuesta metodológica se ha considerado la cuenca endorreica de Padul (Granada, España) como ámbito de estudio piloto. Se trata de una cuenca que, a pesar de albergar uno de los humedales más importantes del sureste peninsular (incluido desde 1989 en el Parque Natural de Sierra Nevada), a lo largo de la historia -y aún en la actualidad- se encuentra sometida a determinadas dinámicas, presiones y riesgos que presentan una notable incidencia en la configuración, dinámica y caracterización de sus paisajes.

\section{Material y métodos}

\section{1 Ámbito de estudio}

Asociada a la Cordillera Bética, la cuenca endorreica de Padul se localiza en la vertiente suroccidental del macizo montañoso de Sierra Nevada (Granada, España). Presenta una extensión de $56 \mathrm{~km}^{2}$ y una altitud media de 775 m.s.n.m. Incluye parte de los términos municipales de Padul, Dúrcal y Cozvijar, que albergan los núcleos urbanos de Padul y El Puntal, Marchena y Cozvíjar respectivamente. La población total es de 10.725 habitantes (INE, 2017).

La cuenca hidrológica se localiza en la divisoria atlántico-mediterránea, entre la Demarcación Hidrográfica del Guadalquivir (subcuenca del río Genil) y la Demarcación Hidrográfica de las Cuencas Mediterráneas Andaluzas (subcuenca del río Guadalfeo). Su nivel de base (719 m.s.n.m.) coincide con un conjunto de reductos lagunares de tipo turbera, agua dulce e hidroperíodo permanente: Turbera y Laguna del Aguadero y Turbera y Lagunas del Agia (también denominados "Humedales y Turberas de Padul" o "Laguna de Padul") (Figura 1). Estos humedales se encuentran incluidos desde 1989 en el Parque Natural de Sierra Nevada. Posteriormente, en 2006, fueron declarados "Humedal de Importancia Internacional" (Humedal Ramsar). 
Figura 1. Mapa de localización de la cuenca endorreica de Padul

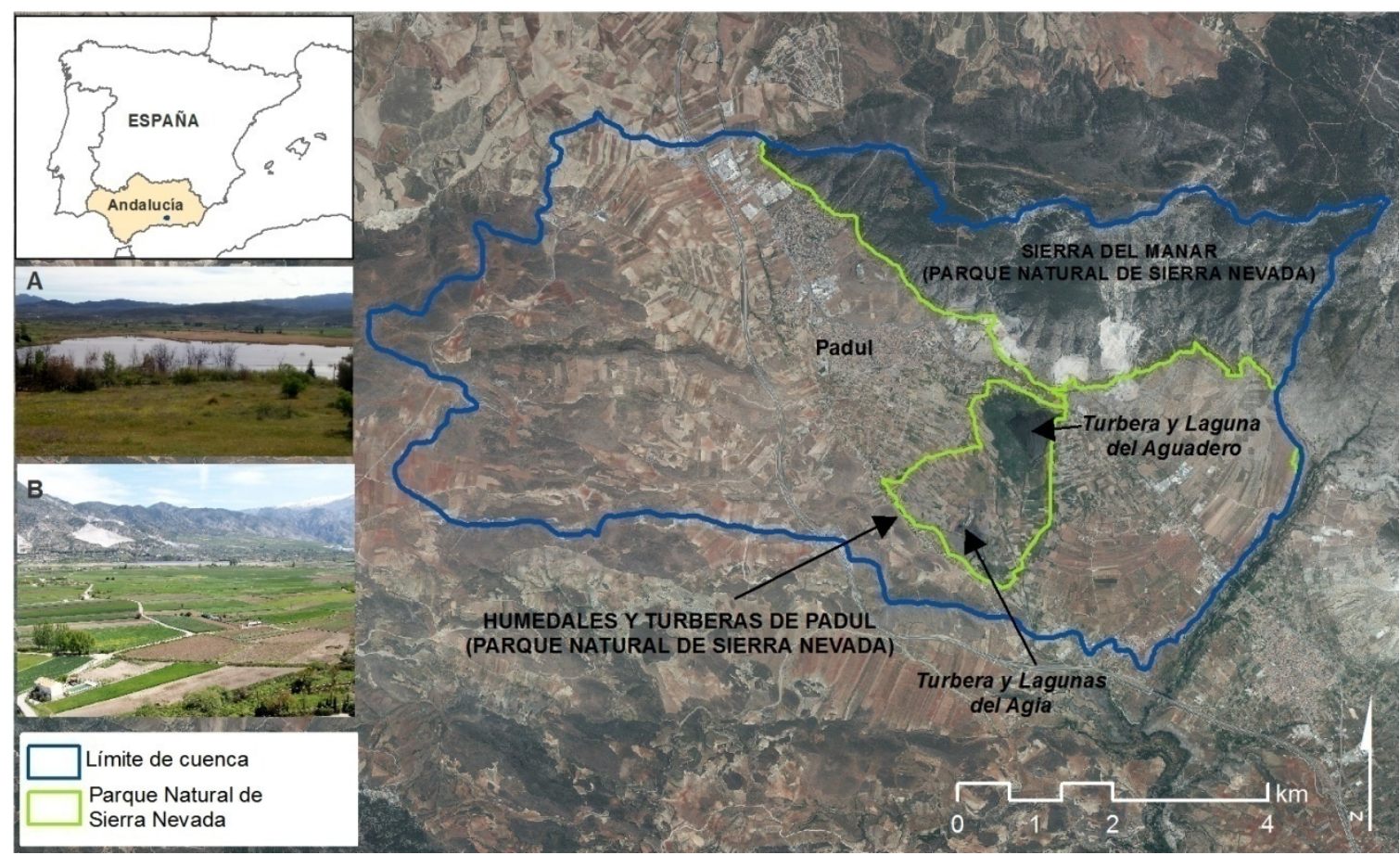

Fuente: elaboración propia a partir de DEA_100 (Datos Espaciales de Andalucía. E. 1:100 000)

y Ortofoto PNOA (2013). Fotografías: (A) Turbera y Laguna del Aguadero.

(B) Panorámica de la depresión y vega de Padul (nivel de base de la cuenca).

La Laguna de Padul ha estado secularmente sometida a una intensa explotación de sus recursos naturales. Destaca, por una parte, el gran proyecto de desecación que tuvo lugar a finales del S.XVIII (1779) por motivos sanitarios y agrícolas; por otra, la explotación minero-industrial de la turba mediante dos canteras a cielo abierto (Turbera del Aguadero y Turbera del Agia), iniciada a mediados del S.XX. Ambos procesos han sido los causantes de una desecación del humedal prácticamente ininterrumpida hasta 2010, momento en que una de las canteras (Turbera del Aguadero) quedó clausurada. A partir del cierre de dicha explotación se ha producido una progresiva regeneración del humedal en el contexto de su cuenca, lo que supone una oportunidad para la identificación, caracterización y cualificación sus paisajes (Arias García, 2016).

\subsection{Aportaciones teórico-metodológicas del Convenio Europeo del Paisaje (CEP) y Lanscape Character Assessment (LCA)}

La ciencia del paisaje se ha caracterizado por la multiplicidad de enfoques conceptuales y metodológicos: enfoque ecológico (Wiens \& Milne, 1989; Forman, 1995; Wu, 2006), perceptual (Lowenthal, 1978; Morgan, 1978; Zube, Sell \& Taylor, 2000), sistémico o integrado (Bertrand, 1968, 1974, 1978), histórico (Aldred \& Fairclough, 2003; Stabbetorp et al., 2007; Lambrick, Hind \& Wain, 2013), etc.; una diversidad que en Europa, a través del CEP (2000), se ha querido 
consensuar con el objetivo de desarrollar una política para proteger, gestionar y ordenar los paisajes.

Por otra parte, como antesala de toda acción paisajística, el Convenio y sus Orientaciones establecen que para profundizar en el conocimiento del paisaje, cada Estado o Parte ha de asumir los siguientes compromisos: identificar los paisajes en todo su territorio (Identificación); analizar sus características, fuerzas y presiones que los transforman (Caracterización), lo que implica un análisis del paisaje desde el punto de vista natural, histórico, cultural y perceptivo-visual; calificar el paisaje teniendo en cuenta sus valores (Cualificación); establecer Objetivos de Calidad Paisajística; y realizar el seguimiento de las transformaciones del paisaje.

En consecuencia, del CEP y sus Orientaciones se desprende la necesidad de comprender y describir las características específicas de cada paisaje en su estado actual, aún reconociendo que cada paisaje es resultado de la interacción de factores naturales y/o humanos; la necesidad de analizar sus procesos evolutivos y la constatación de las dinámicas temporales pasadas, presentes y previsibles; así como la necesidad de reconocer los valores que les otorgan quienes perciben estos paisajes, tanto por parte de expertos como del público en general.

El Convenio designa en su definición de paisaje a cualquier parte del territorio como tal. Por tanto, la identificación, cualificación y el desarrollo de objetivos de calidad pueden ocuparse de todo tipo de paisajes; de ahí también su interés como objeto de análisis. En este sentido, el presente trabajo adopta desde el punto de vista conceptual la definición propuesta por el CEP; y se ocupa, como queda recogido en él, de identificar, caracterizar y cualificar una determinada tipología de paisajes (cuencas endorreicas y humedales asociados) a partir de un estudio de caso.

Por otra parte, y en relación con el procedimiento metodológico LCA (Landscape Character Assessment), Jensen (2005) y Mała Olmo (2008) señalan la existencia de tres etapas teóricometodológicas: (1) Años 70: Landscape Evaluation, mediante aproximaciones generalmente cuantitativas con el fin de determinar la calidad y valor de los paisajes para poder compararlos entre sí; (2) Años 80: Landscape Assessment: se clasifica y describe el carácter del paisaje, es decir, ¿qué hace a un paisaje diferente a otro?; bajo esta concepción, se establecen diferencias entre los paisajes en función de sus características y no de su valor; (3) Años 90: Landscape Character Assessment: el carácter del paisaje se configura ya como concepto central del análisis y la acción paisajística a todas las escalas. Será en 2002 cuando la Countryside Agency and Scottish Natural Heritage publiquen una guía para la estimación del carácter paisajístico: "Landscape Character Assessment: Guidance for England and Scotland" (Swanwick, 2002), cuyo enfoque o método presenta las siguientes características:

- El discurso paisajístico se centra en torno al carácter del paisaje, entendido como la combinación particular, reconocible y consistente de elementos presentes en un determinado paisaje que lo 
hacen diferente a otro. Se trata de identificar las características clave o distintivas de cada paisaje sin atender a una valoración.

- Se diferencia claramente entre los procesos de caracterización y valoración.

- Propone una clasificación del paisaje en torno a Tipos y Áreas paisajísticas (Swanwick, 2002, 2004): Tipos: sistema o constelación de unidades del territorio con un patrón paisajístico particular y homogéneo con respecto a sus características naturales, sociales y culturales. Estas unidades presentan un mismo carácter o combinación de características. Su denominación es más abstracta y su distribución espacial puede ser inconexa; Áreas: espacios geográficos singulares y únicos en los que se desarrolla un particular tipo de paisaje. Cada Área tiene su propio carácter e identidad, por lo que se denominan con nombres de unidades concretas (un topónimo, por ejemplo). Presentan una identidad territorial y paisajística inequívoca, singular y fácilmente reconocible por la población.

La principal aportación de esta metodología es la estimación del carácter paisajístico y la clasificación de los paisajes en Tipos y Áreas de forma iterativa e interescalar (Swanwick, 2002, 2004). El método surge con la finalidad de extender el tratamiento del paisaje a todo el territorio, superando las aproximaciones excepcionalistas o restringidas desde las que anteriormente se abordaba el análisis del paisaje. Como señalan algunos autores, se obvian las aproximaciones orientadas a la determinación de lo excepcional o sobresaliente en relación con los recursos paisajísticos (Lipský \& Romportl, 2007; Gómez Zotano \& Riesco Chueca, 2010; Fairclough, Sarlöv Herlin \& Swanwick, 2018), pues esta clasificación del paisaje en Tipos y Áreas permite: mostrar los aspectos distintivos que individualizan unidades de paisaje y las diferencian de otras, es decir, se trata de determinar y cartografiar paisajes únicos e individuales situados de forma única en una localización particular (Áreas); y explorar los aspectos generales que son compartidos por paisajes distribuidos de forma separada. Ello da lugar a una sistematización basada en semejanzas y conduce a una tipología de paisaje (Tipo).

\subsection{Metodología propuesta}

El método se articula en torno a 2 etapas (Identificación y Caracterización; y Valoración y Propuestas) que se desglosan en un total de 11 fases (Figura 2). 
Figura 2. Etapas y fases de la metodología propuesta

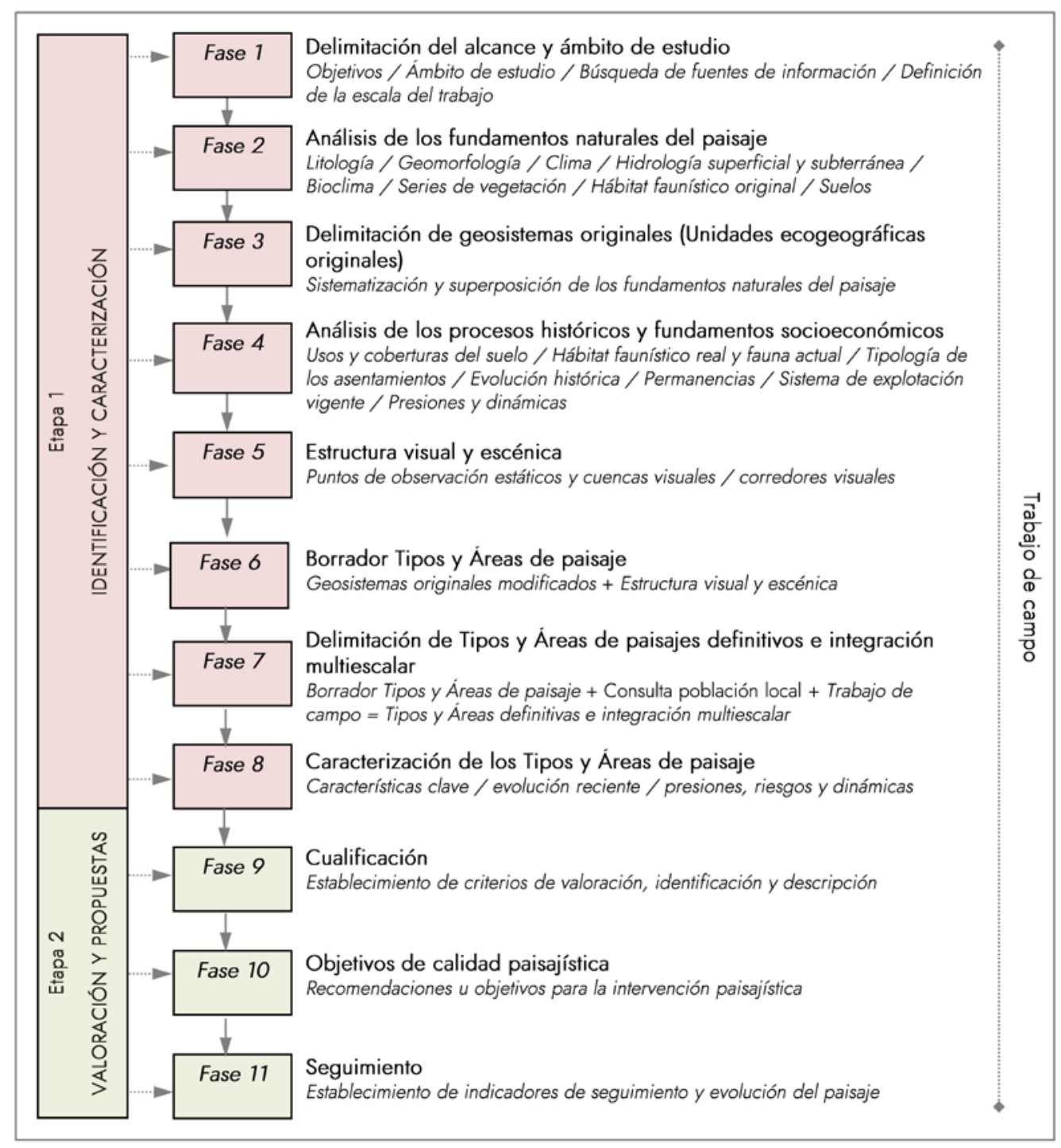

Fuente: elaboración propia

La primera etapa consiste en la identificación, clasificación, caracterización e integración multiescalar de los Tipos y Áreas paisajísticos. Consta de 8 fases:

- Fase 1 o inicial. Definición del alcance y ámbito de estudio: consiste en la definición del área de estudio (delimitación espacial y cartográfica) y la escala de trabajo. La búsqueda de fuentes de información y el establecimiento de un calendario de trabajo de campo constituyen también actividades clave en esta fase inicial del método.

- Fase 2. Análisis de los fundamentos naturales del paisaje: delimitación y descripción de unidades litológicas, geomorfológicas, climáticas, hidrología superficial, unidades hidrogeológicas, termotipos y ombrotipos (aspectos bioclimáticos), series de vegetación, hábitat faunístico original y unidades edafológicas. Para la ejecución de esta fase se consideraron los datos espaciales, servicios y metadatos ofrecidos por la Red de Información Ambiental de 
Andalucía (Rediam), así como cartografía temática especializada (a escala comarcal y subregional) y trabajo de campo.

- Fase 3. Delimitación de geosistemas originales (unidades ecogeográficas originales): la superposición o combinación de la cartografía derivada de las variables analizadas en la fase anterior (fase 1) con la herramienta SIG (ArcGis 10.1), junto con el criterio experto, permite delimitar unidades homogéneas desde el punto de vista de su potencial ecológico y explotación biológica. Aunque esta fase no aparece contemplada en la metodología LCA, a partir de la concepción del análisis sistémico del paisaje o Geosistema, cuyo precursor fue el geógrafo francés George Bertrand (1968, 1974, 1978), se ha introducido el concepto de "geosistema original o unidad ecogeográfica original", que permite una aproximación a los fundamentos o condiciones estructurantes del paisaje previas a la intervención antrópica.

- Fase 4. Análisis de los procesos históricos y fundamentos socioeconómicos del paisaje: esta fase contempla el análisis de las siguientes variables: (1) Usos y coberturas del suelo; (2) Hábitat faunístico real y fauna actual: fauna salvaje, fauna cinegética y ganadería; (3) Tipología de los asentamientos y patrones de distribución; (4) Evolución histórica: principales hitos y procesos históricos clave que han podido contribuir a la generación de un carácter paisajístico concreto; (5) Permanencias: legado histórico cultural que perdura en el territorio y presenta una incidencia en el paisaje y su configuración; (6) Sistema de explotación vigente: comprende el análisis del sistema de explotación agraria - destacando la tipología parcelaria y el tamaño de las explotaciones-, así como la distribución de los montes públicos; (7) Afecciones territoriales; y (8) Presiones y dinámicas: diagnóstico de los procesos de cambio actualmente vigentes con incidencia en la configuración de los paisajes.

- Fase 5. Estructura visual y escénica: se calculan los ámbitos o cuencas visuales a partir de un conjunto de puntos de observación estáticos distribuidos en el área de estudio; pudiendo incorporarse también puntos de observación dinámicos o corredores visuales, tales como vías de comunicación de uso frecuente, senderos, etc.

- Fase 6. Borrador de Áreas y Tipos de paisaje: se combina o superpone la cartografía sistémica (geosistemas originales o unidades ecogeográficas originales) con la información referente a los fundamentos históricos y socioeconómicos analizados en la fase 4. La superposición cartográfica se realiza de manera semiautomática con la herramienta SIG (ArcGis 10.1), incorporándose el análisis experto con la finalidad de incluir los aspectos culturales ligados al paisaje, que al no presentar una localización espacial concreta dificultan su cartografiado.

- Fase 7. Delimitación y denominación de Tipos y Áreas de paisaje definitivos: tras la realización del mapa borrador de posibles Tipos y Áreas de paisaje se contrasta y modifica mediante trabajo de campo y consulta a la población local. La tipificación permite delimitar las unidades de paisaje que son diferentes entre sí en función de un conjunto de atributos diferenciadores, 
independientemente de su ubicación o contexto geográfico (Tipos). Por su parte, las Áreas se corresponden con espacios geográficos singulares y únicos en los que se desarrolla un particular tipo de paisaje. Para llevar a cabo esta clasificación se procede a la ejecución del método combinado de agregación y subdivisión. La agregación sigue un procedimiento paramétrico en el que las primeras unidades básicas (Tipos) se definen mediante una selección de atributos abióticos, bióticos, histórico-funcionales, culturales y escénico-visuales que, resultado de una combinación particular, posteriormente se agrupan en unidades paisajísticas concretas y cuya denominación presenta un reconocimiento social (Áreas). Esta clasificación permite, además, establecer una jerarquía a distintas escalas espaciales (integración multiescalar).

- Fase 8. Caracterización: a partir de la información cuantitativa y cualitativa recopilada en las fases anteriores se describen las características clave de los Tipos y Áreas de paisaje, así como su evolución reciente, presiones, riesgos y dinámicas.

Tras la Ełapa 1 se establece la valoración y significación de los Tipos y Áreas de paisaje así como la definición de posibles objetivos de calidad (Etapa 2). En esta segunda etapa, que consta de tres fases, se ha optado por la estructura sugerida por el Convenio Europeo del Paisaje, lo que ha supuesto reformular las dos últimas fases propuestas por la metodología LCA (establecimiento de criterios de valoración; y valoración), que han sido sustituidas por: cualificación; definición de objetivos de calidad paisajística; y seguimiento y establecimiento de indicadores:

- Fase 9. Cualificación: de acuerdo con las Orientaciones del CEP (Consejo de Europa, 2008), la cualificación consiste en una comparación dialéctica entre los análisis de los expertos y los valores atribuidos por la población al paisaje en el contexto de la existencia de diferentes sistemas de valores y de no-valores, ya estén consolidados o en proceso de definición. Se identifican los valores directos e indirectos que presenta un determinado Tipo o Área de paisaje; para ello, se procede a la sistematización de los valores objetivos (naturales o ecológicos, por ejemplo) y subjetivos (atribuidos al paisaje por parte de la población y que contribuyen a consolidar su identidad). Para la cualificación se han establecido los siguientes criterios de valoración: valores naturales, productivos, histórico-patrimoniales, de uso social, mitológicos o espirituales, simbólicos y estéticos.

- Fase 10. Definición de objetivos de calidad paisajística: establecimiento de posibles líneas de actuación que permitan la protección, gestión y ordenación de un determinado Tipo o Área de paisaje. Se trata de aspiraciones generales (líneas de actuación) que posteriormente podrán ir perfilándose en una lista particularizada de objetivos concretos en función del diagnóstico y las características particulares de cada paisaje.

- Para la definición de objetivos de calidad se han considerado, como marco general, los objetivos propuestos en la Estrategia de Paisaje de Andalucía (EPA) (2012) y sus 17 líneas 
estratégicas $^{1}$. No obstante, cabe señalar que se trata de objetivos genéricos y que no todos son aplicables al ámbito de estudio objeto de este trabajo.

- Fase 11. Seguimiento y establecimiento de indicadores: el CEP sugiere el establecimiento de herramientas para el seguimiento de las transformaciones paisajísticas y la eficacia de las políticas que se adopten en este sentido. En consecuencia, han de definirse una serie de indicadores o parámetros ambientales, culturales y sociales del paisaje que sean comprensibles por la población, políticos y gestores públicos, por lo que se propone un modelo de ficha de seguimiento adaptada a una de las Áreas paisajísticas objeto de estudio pormenorizado.

\section{Desarrollo de la metodología propuesta y resultados}

\subsection{Etapa 1: Identificación, caracterización e integración multiescalar de los paisajes de la cuenca de Padul}

Tras la delimitación del ámbito de estudio, coincidente con los límites naturales de la cuenca hidrológica (cuenca endorreica de Padul, $56 \mathrm{Km}^{2}$ ), se procedió al análisis de los fundamentos naturales del paisaje. Para cada variable del subsistema abiótico y biótico se delimitaron las diferentes unidades o discontinuidades espaciales que directa o indirectamente pudiesen contribuir a la diversidad u homogeneidad paisajística de la cuenca objeto de estudio (Tabla 1).

Para la obtención del mapa de geosistemas originales, en primer lugar se combinaron los mapas relativos al potencial ecológico (Unidades litológicas, Unidades geomorfológicas, Unidades climáticas, Hidrología superficial, Unidades hidrogeológicas y Bioclima -termotipos y ombrotipos-), que condicionan sustantivamente las características del medio biótico; y a continuación, se combinaron aquellas variables que representan la explotación biológica. La superposición o combinación cartográfica permitió la identificación y delimitación de 6 geosistemas originales, que han de entenderse como una aproximación espacial a las condiciones estructurantes de la cuenca previas a la intervención antrópica (Figura 3).

1 Los 7 objetivos de la Estrategia de Paisaje de Andalucía son: 1. Impulsar la recuperación y mejora paisajística del patrimonio natural; 2. Impulsar la recuperación y mejora paisajística del patrimonio cultural; 3. Cualificar los paisajes urbanos; 4. Cualificar los paisajes asociados a actividades productivas; 5. Cualificar las infraestructuras de transporte, energía y comunicaciones; 6. Implementar instrumentos de gobernanza paisajística; 7. Potenciar la sensibilización, educación y la formación en materia de paisaje. Acceso al documento completo: http://www.juntadeandalucia.es/medioambiente/portal_web/web/temas_ambientales/evaluacion_integracion_pla nificacion/planificacion_ambiental/estrategias/estrategia_paisaje/Estrategia_de_Paisaje_de_Andalucia_2012.pdf 


\section{Tabla 1. Síntesis de los fundamentos naturales del paisaje de la cuenca endorreica de Padul: definición de unidades y/o discontinuidades espaciales}

\begin{tabular}{|c|c|}
\hline \multicolumn{2}{|r|}{ SUBSISTEMA ABIÓTICO - POTENCIAL ECOLÓGICO } \\
\hline $\begin{array}{l}\text { Unidades Litológicas } \\
\text { (UL) }\end{array}$ & $\begin{array}{l}\text { UL-1. Calizas y calizo-dolomías masivas y tableadas; UL-2. Dolomías y mármoles } \\
\text { dolomíticos; UL-3. Limos, yesos, arenas y conglomerados; UL-4. Materiales } \\
\text { detríticos y calcarenitas bioclásticas; UL-5. Conglomerados heterométricos con } \\
\text { arenas; UL-6. Turberas; UL-7. Depósitos conglomeráticos de piedemonte; UL-8. } \\
\text { Depósitos aluviales. }\end{array}$ \\
\hline $\begin{array}{l}\text { Unidades Geomorfológicas } \\
\text { (UG) }\end{array}$ & $\begin{array}{l}\text { UG-1. Barrancos y encajamientos fluviales; UG-2. Humedales y Turberas; UG-3. } \\
\text { Fosa tectónica endorreica; UG-4. Abanicos aluviales; UG5. Conos aluviales; UG-6. } \\
\text { Lomas y vaguadas suaves con predominio de limos, yesos, arenas y } \\
\text { conglomerados; UG-7. Lomas calcáreas; UG-8. Colinas suaves con predominio de } \\
\text { materiales detríticos y calcarenitas bioclásticas; UG-9. Cerros abruptos calizo- } \\
\text { dolomíticos; UG-10. Sierras escarpadas dolomíticas con barrancos pronunciados. }\end{array}$ \\
\hline $\begin{array}{l}\text { Unidades Climáticas } \\
\text { (UC) }\end{array}$ & $\begin{array}{l}\text { UC-1. Clima mediterráneo continentalizado seco con predominio de nieblas; UC-2. } \\
\text { Clima mediterráneo continentalizado seco; UC-3. Clima mediterráneo } \\
\text { continentalizado seco-subhúmedo de media montaña. }\end{array}$ \\
\hline $\begin{array}{l}\text { Hidrología Superficial } \\
\qquad(H)\end{array}$ & $\begin{array}{l}\text { H-1. Cursos superficiales con caudal estacional y temporal asociados a barrancos } \\
\text { pronunciados; H-2. Cursos superficiales con caudal permanente asociados a } \\
\text { llanura tectónica endorreica; H-3. Masas de agua de hidroperíodo permanente } \\
\text { (turberas). }\end{array}$ \\
\hline $\begin{array}{l}\text { Unidades Hidrogeológicas } \\
\qquad(\mathrm{UH})\end{array}$ & $\begin{array}{l}\text { UH-1. Acuíferos triásicos carbonatados (alta permeabilidad); UH-2. Acuíferos } \\
\text { miocenos carbonatados (alta permeabilidad); UH-3. Acuíferos miocenos detríicos } \\
\text { (semipermeables); UH-4. Acuíferos pliocenos detríticos (permeabilidad variable); } \\
\text { UH-5. Acuíferos neógeno-cuaternarios detríticos (permeabilidad variable); UH-6. } \\
\text { Acuíferos neógeno-cuaternarios y orgánicos (semipermeables e impermeables). }\end{array}$ \\
\hline $\begin{array}{c}\text { Termotipos (T) } \\
\text { y Ombrotipos (O) }\end{array}$ & $\begin{array}{l}\text { T-1. Termotipo mesomediterráneo inferior; T-2. Mesomediterráneo superior; T-3. } \\
\text { Supramediterráneo inferior; O-1. Hiperhúmedo (azonal); O-2. Seco inferior; O-3. } \\
\text { Seco subhúmedo. }\end{array}$ \\
\hline \multicolumn{2}{|r|}{ SUBSISTEMA BIÓTICO - EXPLOTACIÓN BIOLÓGICA } \\
\hline $\begin{array}{l}\text { Series de Vegetación (SV) y } \\
\text { Comunidades Exoseriales } \\
\text { (CE) }\end{array}$ & $\begin{array}{l}\text { SV-1. Paeonio coriaceae-Querceto rotundifoliae S. Faciación típica, con inclusión } \\
\text { de la serie de la sabina mora: Rhamno myrtifolii-Junipereto phoeniceae S. SV-2. } \\
\text { Berberido hispanicae-Querceto rotundifoliae S. con inclusión de la serie de la } \\
\text { sabina mora: Rhamno myrtifolii-Junipereto phoeniceae S.; SV-3. Serie riparia de la } \\
\text { mimbre roja (Salix purpurea subsp. lambertiana): Saliceto neotriche S. SV-4. Serie } \\
\text { riparia del álamo blanco (Populus alba): Rubio tinctori-Populeto albae S. SV-5. } \\
\text { Serie del olmo común (Ulmus minor): Hedero-Ulmeto minoris S. CE-1. } \\
\text { Comunidades acuáticas; CE-2. Comunidades terofíticas; CE-3. Comunidades } \\
\text { helofíticas. }\end{array}$ \\
\hline Hábitat Faunístico (H) & $\begin{array}{l}\text { F-1. Fauna asociada a los espacios serranos (monte mediterráneo) y piedemontes; } \\
\text { F-2. Fauna asociada al bosque galería; F-3. Fauna asociada a los humedales y } \\
\text { turberas. }\end{array}$ \\
\hline Unidades Edafológicas (UF) & $\begin{array}{l}\text { UF-1. Regosoloes lépticos; UF-2. Leptosoles réndzicos y regosoloes calcáricos; UF- } \\
\text { 3. Leptosoles réndzicos y regosoles lépticos; UF-4. Leptosoles líticos y regosoles } \\
\text { lépticos; UF-5. Leptosoles líticos y regosoles calcáricos; UF-6. Regosoles } \\
\text { calcáricos; UF-7. Cambisoles calcáricos y luvisoles cálcicos; UF-8. Luvisoles } \\
\text { cálcicos; UF-9. Fluvisoles calcáricos; UF-10. Histosoles fíbricos. }\end{array}$ \\
\hline
\end{tabular}

Fuente: elaboración propia 
Figura 3. Superposición cartográfica de los fundamentos naturales del paisaje y delimitación de Geosistemas originales (G)

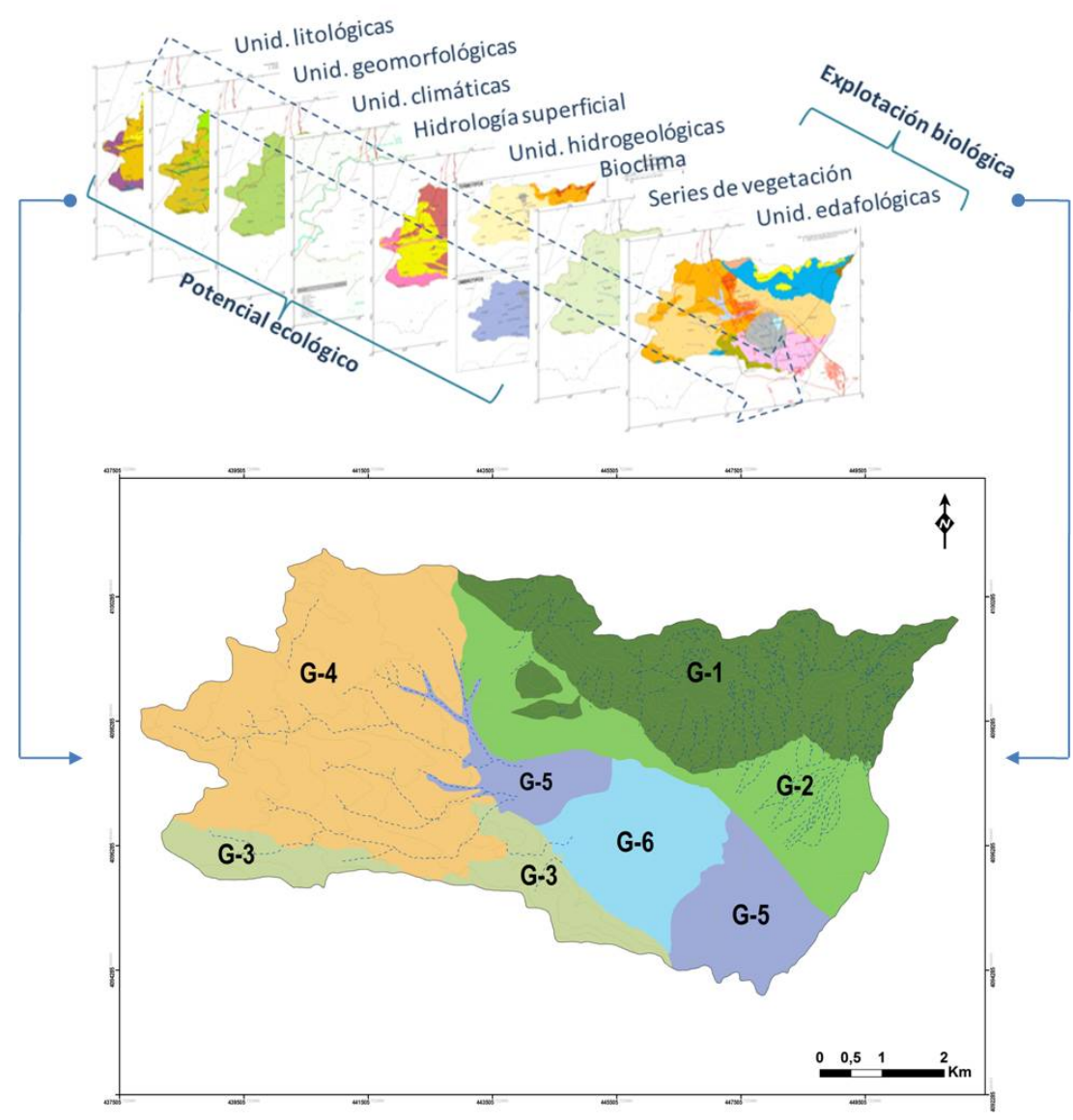

Leyenda: G-1: Laderas dolomíticas escarpadas con encinares y pinares-sabinares meso y supramediterráneos secos; G2: Piedemontes conglomeráticos con encinares y pinares-sabinares mesomediterráneos secos. G-3: Cerros y lomas calcáreas con encinares y pinares-sabinares mesomediterráneos secos. G-4: Lomas y vaguadas detríticas y carbonatadas con encinares y pinares-sabinares mesomediterráneos secos, bosque galería y fauna riparia; G-5: Llanura aluvial en fondo de cuenca endorreica con ripisilva mesomediterránea y fauna riparia; G-6: Turberas con vegetación lacustre-palustre mesomediterránea hiperhúmeda y avifauna acuática.

\section{Fuente: elaboración propia}

A continuación se procedió al análisis de los fundamentos históricos y socioeconómicos del paisaje. En primer lugar se elaboró un Mapa de usos del suelo a escala 1:25000 a partir de dos categorías básicas: espacios naturales o seminaturales (incluyen espacios con cubierta vegetal espontánea así como aquellos con escasa o nula cobertura vegetal) y espacios antropizados o artificiales (incluyen los espacios de uso agrario, urbano-industrial, equipamientos e infraestructuras). Se utilizó como base el Mapa de Usos y Coberturas Vegetales del Suelo de Andalucía (MUCVA) del año 2007 (E. 1:25 000) elaborado por la Consejería de Medio Ambiente y Ordenación del Territorio de la Junta de Andalucía, aunque fue actualizado mediante fotointerpretación y trabajo de 
campo. La elaboración de este mapa permitió comparar los usos del suelo y coberturas actuales de la cuenca en relación con los geosistemas originales (Figura 4).

Figura 4. Mapa de Usos y Coberturas del Suelo (simplificado) (2016) y correspondencia con los geosistemas originales o unidades ecogeográficas originales. Cuenca de Padul

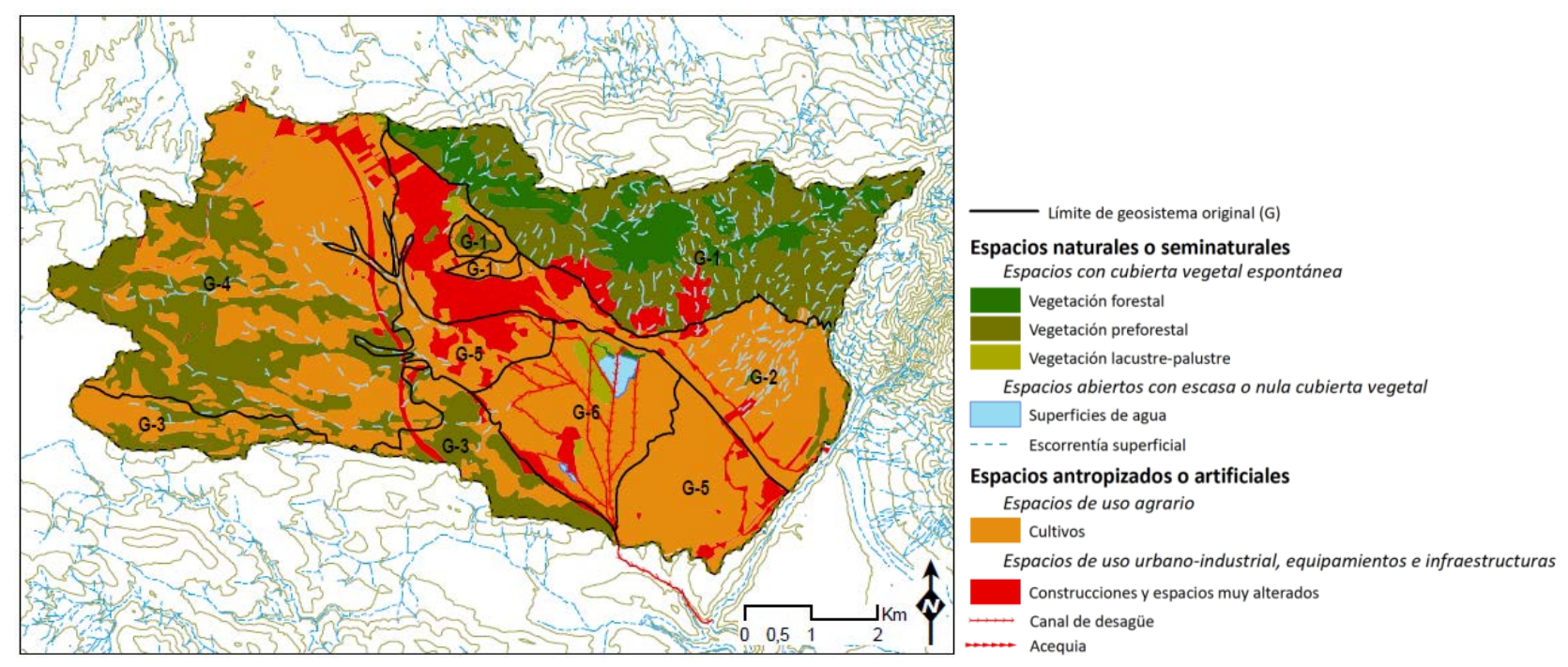

Fuente: adaptado y actualizado de MUCVA (2007)

Atendiendo al mapa anterior (Figura 4), cabe destacar el predominio de los espacios antropizados o artificiales, que ha generado una relevante simplificación geosistémica en el conjunto de la cuenca. Destacan especialmente los espacios de uso agrario (cultivos), que dominan el $40.2 \%$ del ámbito de estudio. Respecto a los espacios de uso urbano-industrial, equipamientos e infraestructuras (construcciones y espacios muy alterados), destaca el uso urbano (178 Ha) y las explotaciones minero-extractivas. En este último caso, son 8 las explotaciones extractivas identificadas, que corresponden a dos tipos: extracción de áridos (dolomías) y extracción de turba (en los humedales y turberas del fondo de la depresión). El primer tipo ocupa una superficie de 113.2 $\mathrm{Ha}$, mientras que la superficie ocupada por las canteras de turba se reduce a $17 \mathrm{Ha}$ en la actualidad (no obstante, hasta 2010 el fondo de la cuenca contaba con otra explotación de turba de $16 \mathrm{Ha}$, desde entonces clausurada).

En relación a la cubierta forestal, su área de distribución es relativamente coincidente respecto a su área original (G-1: laderas dolomíticas escarpadas con encinares y pinares-sabinares meso y supramediterráneos secos-subhúmedos). No obstante, si en términos de superficie no se han producido cambios relevantes, sí que ha tenido lugar una notable simplificación de especies y una reducción de la densidad de las masas arbóreas. Como cambio más significativo respecto a su estructura natural cabe señalar que la cubierta vegetal no se corresponde en la actualidad con la vegetación potencial propia de este sector, perteneciente a las series béticas de la encina (Paeonio coriaceae-Querceto rotundifoliae S.) y del pinar-sabinar edafoxerófilo (Rhamno myrtifolii-Junipereto 
phoeniceae S). En consecuencia, el tapiz vegetal actual se corresponde con pinares de repoblación donde prevalece el pino carrasco (Pinus halepensis) y algunos ejemplares de pino resinero (Pinus pinaster). A diferencia de las masas forestales, los matorrales o vegetación preforestal adquieren una mayor distribución en la cuenca, tanto entre las masas forestales del geosistema 1, como de forma dispersa en los geosistemas 3 y 4.

Por su parte, el geosistema 6 -que incluye los humedales y turberas- ha sufrido también notables cambios si se comparan sus elementos y estructura original respecto a los usos y coberturas actuales. Por su carácter lacustre-palustre, alberga el sistema más complejo de infraestructuras hidráulicas cuya finalidad ha sido la de desecar el primigenio humedal e incrementar la superficie cultivable. Este proceso, con un profundo carácter histórico, ha desencadenado, por una parte: una notable reducción de la superficie ocupada originalmente por comunidades de carrizales, juncales y espadañales, que en la actualidad sólo supone el $0.8 \%$ de la cuenca $(45.5 \mathrm{Ha})$ como consecuencia de la roturación de tierras; por otra, un retroceso de la vegetación acuática derivado de la desecación de las superficies de aguas libres. En relación con el actual uso agrícola imperante en el G-6, habría que añadir dos explotaciones de turba que, a modo de cantera a cielo abierto, han contribuido desde mediados del S.XX a la transformación ambiental y paisajística del humedal.

De acuerdo con el procedimiento metodológico propuesto, se elaboró también el Mapa de hábitat faunístico real y fauna actual (incluyendo la zonificación y distribución de la fauna salvaje, cinegética y ganadera) y el Mapa de tipología de los asentamientos y patrones de distribución. Por otra parte, tras la búsqueda y recopilación de fuentes históricas locales y comarcales se llevó a cabo un minucioso análisis de los procesos históricos clave acontecidos en la cuenca objeto de estudio, especialmente de aquellos relacionados directamente con la Laguna de Padul, que constituye el elemento articulador de su cuenca hidrológica asociada. De este análisis se derivó el Mapa de permanencias o de legado histórico-cultural.

Por su notable incidencia en la configuración de los paisajes actuales, entre los principales procesos de transformación histórica cabe destacar el gran proyecto de desecación del humedal de $1779^{2}$. La justificación de este proyecto era fundamentalmente de tipo económico: incremento de tierras cultivables y posibilidad de una zona de pastoreo de reses que suministrarían carne a la ciudad de Granada. En lo que respecta a las motivaciones sanitarias, la desecación acabaría con las fiebres endémicas y enfermedades características asociadas a los humedales. Por el contrario, los argumentos en contra de la desecación aludían a dos posibles problemas derivados de la misma:

2 Libro Capitular de Granada, 1779, folio 109 vuelta, reunión del 15 de junio, en la que se nombran peritos para el reconocimiento de la laguna: dos médicos para los problemas de salud y un agricultor para estudiar las tierras y posibles cultivos. Folios 130-136, correspondientes a la reunión del 17 de agosto, donde se celebró la votación del proyecto de desecación. 
la negación al derecho de propiedad sobre el agua por parte del propietario de la laguna (Conde de Villamena); y el desconocimiento de las posibles consecuencias que podría desencadenar un proyecto de tal envergadura (pues cabría la posibilidad de perjudicar a los agricultores cuyas tierras se localizaban en áreas cercanas a las obras de desecación).

La aprobación y ejecución de este proyecto debe entenderse como una de las claves principales de transformación paisajística del humedal: a partir de 1779 se construyó un complejo sistema de canales de desagüe o "madres" que se entrecruzaban entre sí permitiendo su desagüe a través de un canal principal o Madre Maestra (Villegas Molina, 1967; Sánchez del Árbol, 2009; Arias García, 2016). Una vez desecado, se produjo una microparcelación de las tierras que se explotaron bajo régimen de arrendamiento o colonato; generándose así un minifundismo que persiste en la actualidad y que constituye una de las claves paisajísticas fundamentales de la vega y humedales de Padul.

Además de la actividad agrícola, que fue incrementándose conforme avanzaba la desecación del humedal, habría que añadir otra actividad clave para la comprensión del paisaje actual de los humedales y turberas: la explotación de canteras de turba. En este sentido, son diversas las fuentes históricas que reflejan los intentos de explotación de las turberas de Padul como combustible, al menos desde finales del S.XVIII (Arias García, 2016). No obstante, será a partir de 1956 cuando la explotación se lleve a cabo de forma continuada por parte de dos compañías (Turbera del Aguadero y Turbera del Agia), ambas con una concesión administrativa hasta el año 2034, aunque sólo la segunda permance activa en la actualidad y genera un "micropaisaje" industrial que contrasta con el entorno lacustre-palustre.

Con la finalidad de identificar de forma progresiva aquellas discontinuidades espaciales útiles para identificar los Tipos y Áreas de paisaje, se elaboró también un Mapa de explotación vigente (que incluye el sistema de explotación agraria, tipología parcelaria, tamaño de las explotaciones y distribución de los montes públicos), un Mapa de afecciones territoriales, así como un Mapa de presiones y dinámicas recientes que sintetiza, a modo de diagnosis, los procesos territoriales actualmente vigentes en la cuenca y que son susceptibles de generar cambios en sus paisajes (Figura 5).

Posteriormente se procedió al análisis de la estructura visual y escénica de la cuenca, que tiene como objetivo detectar, por una parte, hasta que punto coinciden los límites de la cuenca hidrológica y las cuencas visuales obtenidas a partir de los puntos de observación (PO) seleccionados, correspondientes a los principales miradores y observatorios de los humedales y turberas; por otra, determinar aquellos sectores de la cuenca que presentan una mayor o menor exposición visual (lo que repercute directamente en la fragilidad visual). Para el cálculo de las cuencas visuales se utilizó el Modelo Digital del Terreno de alta resolución (MDT05/MDT05- 
LIDAR. Año 2010) disponible en el Centro Nacional de Información Geográfica (CNIG). Se calculó el ámbito visual de cada PO con la herramienta para cuencas visuales 3D Analyst del programa ArcGis 10.1. Para cada PO se tuvo en cuenta un factor Z (altura del punto de observación) de $1.60 \mathrm{~m}$ (altura media del ojo humano). En este sentido, si a modo de ejemplo se considera la intervisibilidad interna de los humedales y turberas (Figura 6) puede comprobarse que el $86.5 \%$ de la cuenca presenta una visibilidad media y alta, por lo que presenta un carácter visual cerrado o autocontenido.

\section{Figura 5. Mapa de presiones y dinámicas recientes. Cuenca endorreica de Padul}

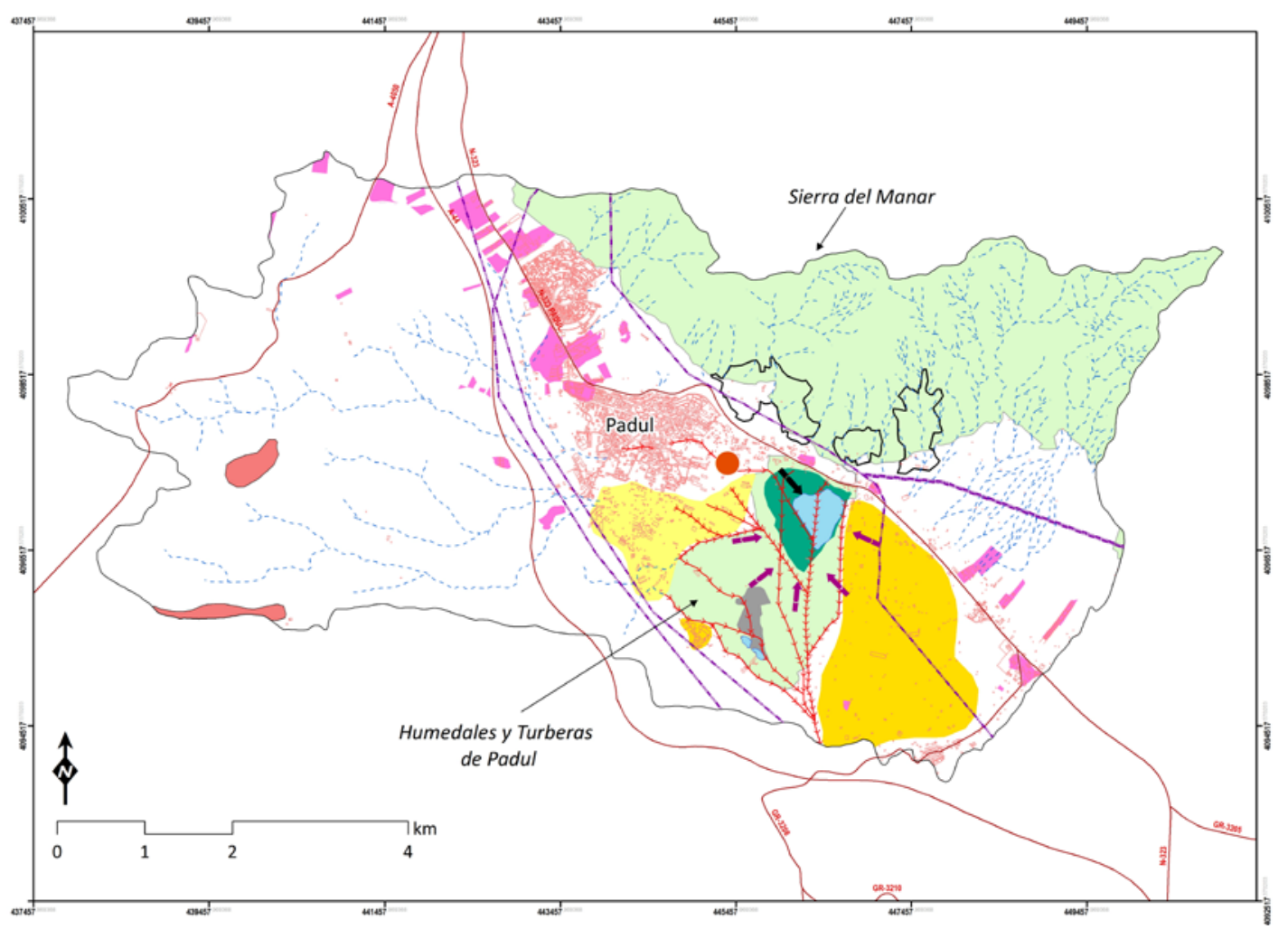

Recuperación del humedal

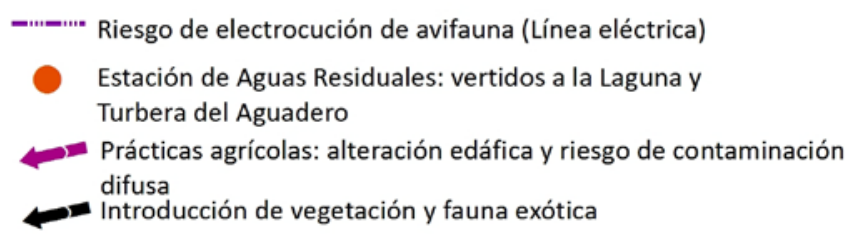

Cantera de turba: eliminación de la cubierta vegetal, desecación del humedal y alteración morfológica

Cantera de áridos: eliminación de la cubierta vegetal, modificación de la escorrentía superficial y contaminación atmosférica Áreas de concentración industrial Área de expansión de infraestructuras energéticas (aerogeneradores)

Expansión del núcleo urbano de Padul Incremento de edificaciones dispersas

Signos convencionales

\begin{tabular}{ll}
$\square$ Parque Natural de Sierra Nevada $\longleftrightarrow$ Canal de desagüe \\
\hline Masa de agua (laguna) & $\longrightarrow$ Vias de comunicación \\
$\ldots-\ldots$ - Escorrentía superficial & Edificaciones
\end{tabular}

Fuente: elaboración propia 
Figura 6. Mapa de Intervisibilidad Interna de los Humedales y Turberas

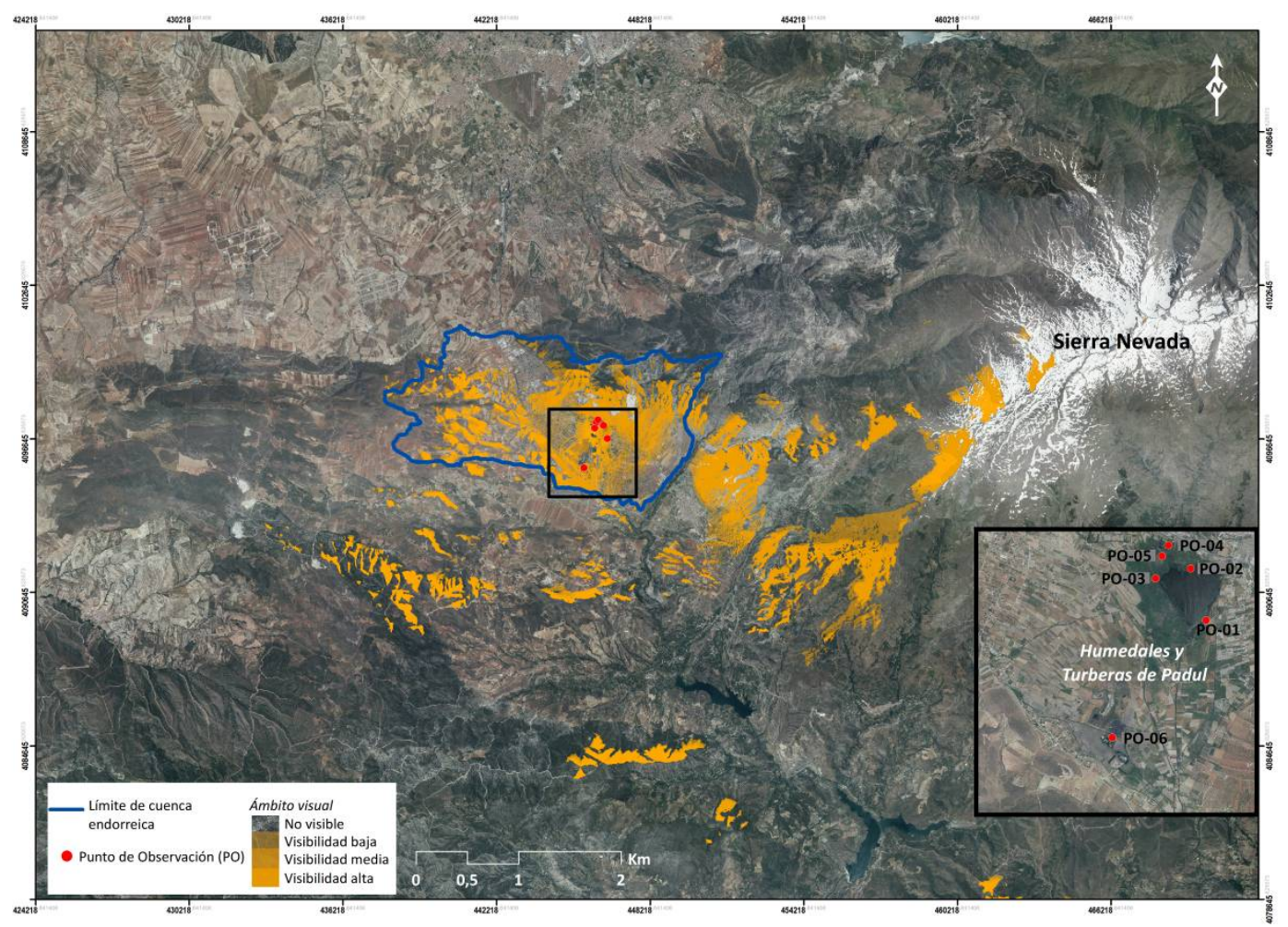

Fuente: elaboración propia a partir del MDT (CNIG) de las cuatro hojas correspondientes

al ámbito visual de la cuenca de Padul (hojas 1026, 1027, 1041 y 1042 del MTN50)

Tras el análisis de los fundamentos naturales, históricos, socioeconómicos y escénico-visuales del paisaje se procedió a la elaboración del Mapa borrador de Tipos y Áreas de paisaje a escala comarcal. Para ello, se combinó la cartografía sistémica (geosistemas originales o unidades ecogeográficas originales) con la información antrópica anteriormente analizada (usos del suelo, aspectos visuales y escénicos, aspectos culturales de percepción y discurso). La superposición cartográfica se realizó de manera semiautomática con la herramienta SIG, incorporándose el análisis experto con la finalidad de incluir los aspectos culturales ligados al paisaje. Este mapa borrador permitió identificar 4 posibles conjuntos de Tipos y Áreas de paisaje:

- Laderas abarrancadas con pinar, matorral y canteras de áridos con amplia exposición visual (Posible Tipo/s) correspondientes a la Sierra del Manar (Posible Área/s).

- Piedemontes con uso agrícola, urbano e industrial con amplia visibilidad (Posible Tipo/s) de transición entre la sierra y la depresión tectónica de Padul (Posible Área/s a cotejar con trabajo de campo y consulta pública).

- Depresión tectónica con cultivos, uso urbano-industrial y reductos lagunares con exposición visual media-alta (Posible Tipo/s) correspondientes con la Depresión de Padul (Posible Área/s). 
- Sucesión de lomas, colinas y vaguadas con matorral y cultivos de secano con intervisibilidad heterogénea (Posible Tipo/s) que se distribuyen por el sector occidental y meridional de la cuenca (Posible Área/s a cotejar con trabajo de campo y consulta pública).

Posteriormente, previa delimitación e integración multiescalar de los Tipos y Áreas de paisaje se procedió a la consulta de clasificaciones paisajísticas de referencia para el ámbito de estudio en el contexto nacional, regional y comarcal: Atlas de los Paisajes de España (2004), Mapa de los Paisajes de Andalucía (2005) y Catálogo de los Paisajes de la Provincia de Granada (2015), que sirvieron como base para la posterior zonificación paisajística de la cuenca de Padul.

El Atlas de los paisajes de España constituye un marco de referencia en la identificación de los grandes conjuntos paisajísticos a escala regional y comarcal partir de 3 niveles taxonómicos: Nivel 1. Asociaciones de tipos de paisaje, cuyo nexo común presenta un carácter fisiográfico, morfológico o climático; Nivel 2. Tipos de paisaje, a partir de la agrupación de unidades de paisaje similares en su estructura y organización; y Nivel 3. Paisajes o unidades de paisaje, que presentan una configuración territorial diferenciada, única y singular. Considerando la propuesta del atlas, la cuenca de Padul se insertaría en la siguiente clasificación paisajística (Tabla 2):

Tabla 2. Clasificación de los paisajes de la cuenca de Padul a partir del Atlas de los Paisajes de España

\begin{tabular}{|c|c|c|c|}
\hline \multicolumn{2}{|c|}{ ESCALA REGIONAL } & ESCALA COMARCAL \\
\hline $\begin{array}{c}\text { ASOCIACIONES } \\
\text { DE TIPOS DE PAISAJE }\end{array}$ & TIPOS DE PAISAJE & SUBITPO & $\begin{array}{c}\text { PAISAJES (UNIDADES } \\
\text { DE PAISAJE) }\end{array}$ \\
\hline $\begin{array}{c}\text { Macizos montañosos de las } \\
\text { Cordilleras Béticas (3) }\end{array}$ & $\begin{array}{c}\text { Macizos montañosos } \\
\text { béticos (7) }\end{array}$ & $\begin{array}{c}\text { Macizo } \\
\text { montañoso } \\
\text { de Sierra } \\
\text { Nevada }\end{array}$ & $\begin{array}{c}\text { Sierra Nevada granadina } \\
\text { central (7.02) }\end{array}$ \\
\hline $\begin{array}{c}\text { Cuencas, hoyas y } \\
\text { depresiones (10) }\end{array}$ & $\begin{array}{c}\text { Hoyas y depresiones } \\
\text { bético-alicantinas (42) }\end{array}$ & Andaluzas & $\begin{array}{c}\text { Laderas alomadas de Jayena } \\
\text { (42.05) }\end{array}$ \\
\cline { 3 - 4 } & Campiñas del Sur de la \\
vega de Granada (42.06)
\end{tabular}

Fuente: elaboración propia a partir del Atlas de los Paisajes de España (2004)

En el ámbito regional, el Mapa de los paisajes de Andalucía (2005) constituyó también un marco de referencia para la clasificación-marco de las áreas y tipos de paisaje del ámbito de estudio. Este mapa se articula en dos niveles de representación gráfica de los paisajes andaluces. En un primer

3 El número entre paréntesis se corresponde con la nomenclatura utilizada en el Atlas de los paisajes de España. 
nivel, se identifican 85 ámbitos paisajísticos a partir de criterios físico-ambientales y socio-territoriales para cuya denominación se alude a topónimos de amplio reconocimiento social. Estos ámbitos paisajísticos se agrupan posteriormente en 19 áreas paisajísticas, agrupadas a su vez en 5 grandes categorías de paisaje: serranías; campiñas; altiplanos y subdesiertos esteparios; valles, vegas y marismas; y litoral. En un segundo nivel, el mapa distingue 35 unidades fisionómicas agrupadas según los componentes paisajísticos predominantes: unidades fisionómicas con predominio de cobertura vegetal o naturalizada; con predominio de los aprovechamientos agrícolas; con predominio de las geoformas; y construcciones y espacios muy alterados.

Atendiendo a estos dos niveles de reconocimiento paisajístico, la cuenca de Padul se integraría en los siguientes niveles y jerarquías en el contexto de los paisajes andaluces: Nivel 1 (serranías; y valles, vegas y marismas - categorías paisajísticas-; serranías de montaña media; vegas y valles intramontanos; y vegas, valles y marismas interiores -áreas paisajísticas-; vertientes occidentales de Sierra Nevada; Sierras de Tejeda-Almijara; Valle de Lecrín; y Depresión y Vega de Granada ámbitos paisajísticos-); y Nivel 2 (cobertura vegetal forestal, aprovechamientos agrícolas, geoformas y construcciones y espacios muy alterados - unidades fisionómicas-).

Para la clasificación-marco a escala de detalle (ámbito comarcal) se consideró el Catálogo de los Paisajes de la Provincia de Granada (2015). A escala subregional, este catálogo identifica 10 tipologías paisajísticas básicas (Tipos) atendiendo a criterios de altitud, litología, tipos climáticos, clases morfológicas y gradación antrópica. Además de los criterios anteriores, se incorporan otros como la visibilidad, pendientes, unidades fisionómicas, hábitat construido y tamaño del parcelario, con la finalidad de establecer 23 subtipos paisajísticos a escala comarcal (Subtipos). Finalmente, se identifican 13 áreas de paisaje atendiendo a criterios de identidad territorial y paisajística fácilmente reconocibles por la población (Áreas). De acuerdo con este catálogo, la cuenca de Padul se insertaría en los siguientes Tipos, Subtipos y Áreas de Paisaje (Tabla 3). 
Tabla 3. Clasificación de los paisajes de la cuenca de Padul

a partir del Catálogo de Paisajes de la Provincia de Granada

\begin{tabular}{|c|c|c|}
\hline TIPOS PAISAJÍSTICOS BÁSICOS & SUBTIPOS DE PAISAJE & $\begin{array}{l}\text { ÁREAS DE } \\
\text { PAISAJE }\end{array}$ \\
\hline $\begin{array}{l}\text { Macizos montañosos y vertientes } \\
\text { supramediterráneas } \\
\text { de dominante forestal }\end{array}$ & Macizos montañosos calizos supramediterráneos & \multirow{5}{*}{ 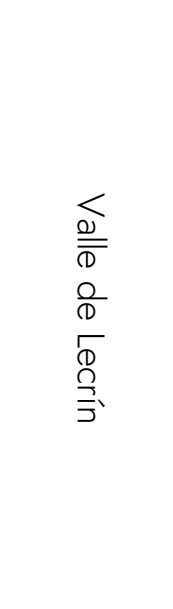 } \\
\hline $\begin{array}{l}\text { Sierras y colinas con coberturas } \\
\text { agrícolas y vegetación natural }\end{array}$ & $\begin{array}{l}\text { Laderas montañosas mesomediterráneas de } \\
\text { dominante natural con cultivos de secano }\end{array}$ & \\
\hline $\begin{array}{l}\text { Valles y depresiones } \\
\text { intramontañosos }\end{array}$ & $\begin{array}{c}\text { Valles intramontañosos con mosaico de regadío } \\
\text { y espacios mixtos en secano }\end{array}$ & \\
\hline \multirow{2}{*}{ Depresión y vega de Granada } & $\begin{array}{c}\text { Colinas y lomas en materiales detríticos con } \\
\text { cultivos de secano mixtos }\end{array}$ & \\
\hline & Vegas interiores con mosaicos de regadíos & \\
\hline
\end{tabular}

Fuente: elaboración propia a partir del Catálogo de Paisajes de la Provincia de Granada (2015)

Previa consideración de las clasificaciones-marco para la identificación de los paisajes a distintas escalas espaciales, el trabajo de campo, la consulta toponímica local y comarcal (catastro, mapas topográficos) y, especialmente, la consulta directa a la población (aspecto clave para la denominación de las Áreas de paisaje a escala local), permitieron modificar el mapa borrador hasta que se consiguieron delimitar con precisión los Tipos y Áreas de paisaje de la cuenca objeto de estudio, su denominación e integración multiescalar.

Se establecieron 4 niveles de integración correspondientes a las siguientes escalas de referencia: supraregional, regional, comarcal o supralocal y local; permitiendo la ejecución del proceso iterativo en Tipos (T) y Áreas (A) que se desprende de la metodología LCA. Los Tipos y Áreas más extensas en superficie incluyen de forma jerarquizada a los Tipos y Áreas de tamaño inmediatamente inferior. En cada nivel escalar se realiza una zonificación de Tipos seguida de otra en Áreas, de tal manera que existen tantas capas de Tipos y Áreas como niveles escalares. Esta clasificación presenta una diferenciación entre lo temático (Tipo) y lo espacial (Área). Los Tipos reflejan los factores dominantes del paisaje, mientras que las Áreas suelen tener cierto arraigo y reconocimiento socio-cultural mediante, por ejemplo, un topónimo (Tabla 4).

Considerando la zonificación paisajística e integración multiescalar propuesta en la Tabla 4 para la cuenca objeto de estudio, a escala supraregional (Nivel 1. Escala $\approx 1 / 1000000$ ) se identificó un Tipo de paisaje (T_1. Cordilleras alpinas circunmediterráneas) en el que se inserta la Cordillera Bética como un Área de paisaje específica (A_1). Teniendo en cuenta la escala de este primer nivel, el acercamiento a los Tipos y Áreas de paisaje es muy básico, por lo que su clasificación se 
fundamenta en identificadores morfoestructurales y biogeográficos, aunque puede considerarse también la trascendencia cultural.

A escala regional (Nivel 2. Escala $\approx 1 / 200000-1 / 100000$ ), se identificaron dos Tipos paisajísticos (T_2.1. Alta montaña mediterránea de dominante agrícola y forestal; y T_2.2. Depresiones intramontañosas mediterráneas de dominante agrícola y urbana) que, siguiendo el proceso iterativo, se desagregaron en dos Áreas (A_2.1. Sierra Nevada; y A_2.2. Depresión de Padul-Dúrcal). A este nivel, la clasificación paisajística obedece a la combinación de elementos abióticos y bióticos con una agrupación de usos del suelo que adquiere prominencia a escalas medias.

\section{Tabla 4. Zonificación paisajística a distintos niveles y escalas de integración espacial}

\begin{tabular}{|c|c|}
\hline \multicolumn{2}{|c|}{ NIVEL 1. Escala supraregional ( $\approx 1 / 1000000)$} \\
\hline TIPO_1 & ÁREA_1 \\
\hline $\begin{array}{l}\text { Supone el acercamiento más básico al paisaje. Éste presenta } \\
\text { una gran extensión superficial y sus características están } \\
\text { determinadas por las grandes morfoestructuras y dominios } \\
\text { biogeográficos, considerándose también la trascendencia } \\
\text { cultural. }\end{array}$ & $\begin{array}{l}\text { Gran unidad fisiográfica con identidad propia. Su } \\
\text { denominación hace alusión a la toponimia de las } \\
\text { grandes estructuras del relieve o la hidrografía. En } \\
\text { ocasiones, cuando la identidad formal se } \\
\text { sobrepone a los rasgos físicos, la denominación } \\
\text { obedece a demarcaciones de orden administrativo } \\
\text { o económico. }\end{array}$ \\
\hline \multicolumn{2}{|c|}{ NIVEL 2. Escala regional ( $\approx 1 / 200000-1 / 100000)$} \\
\hline TIPO_2 & ÁREA_2 \\
\hline $\begin{array}{l}\text { El paisaje está determinado por unas variables abióticas } \\
\text { estables e independientes y su correlación con los grandes } \\
\text { usos del suelo (variable de origen antrópico más inestable y } \\
\text { dependiente). } \\
\text { Las mesoestructuras se definen en el interior de una unidad } \\
\text { macroestructural. Se combinan elementos abióticos y bióticos } \\
\text { con una agrupación de usos del suelo que adquiere } \\
\text { prominencia a escalas medias. }\end{array}$ & $\begin{array}{l}\text { La asignación del nombre procurará acudir a una } \\
\text { denominación tradicional o administrativa con la } \\
\text { finalidad de fortalecer la identidad paisajística y } \\
\text { consensuar directrices territoriales marcadas por las } \\
\text { políticas regionales de ordenación. }\end{array}$ \\
\hline \multicolumn{2}{|c|}{ NIVEL 3. Escala comarcal o supralocal ( $\approx 1 / 50000-1 / 25000)$} \\
\hline TIPO_3 & ÁREA_3 \\
\hline $\begin{array}{l}\text { Los Tipos correspondientes a este nivel comienzan a registrar } \\
\text { en toda su expresión y extensión una combinación de } \\
\text { potencial abiótico, explotación biótica y sistema de uso } \\
\text { antrópico lo suficientemente relevante como para comprender } \\
\text { el paisaje. Elementos como el relieve, bioclima, suelos, usos y } \\
\text { aprovechamientos antrópicos se utilizan generalmente para } \\
\text { identificar y caracterizar los paisajes de este nivel. }\end{array}$ & $\begin{array}{l}\text { En estas Áreas, asociadas a unidades topográficas } \\
\text { de tamaño medio, los componentes territoriales de } \\
\text { mayor magnitud se desdibujan y no pueden ser } \\
\text { percibidos. En consecuencia, su denominación } \\
\text { debe acercarse a la toponimia utilizada por la } \\
\text { población comarcal con la finalidad de fortalecer la } \\
\text { identidad paisajística. }\end{array}$ \\
\hline
\end{tabular}




\begin{tabular}{|c|c|}
\hline \multicolumn{2}{|c|}{ NIVEL 4. Escala local ( $\approx 1 / 10000-1 / 5000)$} \\
\hline $\begin{array}{l}\text { TIPO_4 } \\
\text { Las tipologías paisajísticas reconocidas en este último nivel de } \\
\text { la jerarquía presentan una extensión superficial reducida y } \\
\text { proceden de la combinación de atributos formales y } \\
\text { funcionales de distinta naturaleza (dependiendo de las } \\
\text { características del ámbito de estudio). } \\
\text { Elementos como la topografía (altitud, pendiente), litología, } \\
\text { fisiografía, bioclima, vegetación o edafología, junto con } \\
\text { referencias a los usos y aprovechamientos del suelo se utilizan } \\
\text { para su denominación. Teniendo en cuenta el detalle que } \\
\text { ofrece esta escala, se incorpora también la alusión al } \\
\text { componente visual y escénico. }\end{array}$ & $\begin{array}{l}\text { ÁREA_4 } \\
\text { La denominación del Área responde a la } \\
\text { terminología popular utilizada por la población } \\
\text { local. En consecuencia, dicha denominación puede } \\
\text { hacer referencia tanto a elementos de base natural } \\
\text { como a hechos de origen antrópico (ejemplo, un } \\
\text { núcleo de población o una propiedad). La consulta } \\
\text { pública resulta fundamental para su denominación. }\end{array}$ \\
\hline
\end{tabular}

Fuente: adaptado de Gómez-Zotano et al. (2018)

Figura 7. Mapa de Áreas de paisaje (escala comarcal). Cuenca endorreica de Padul

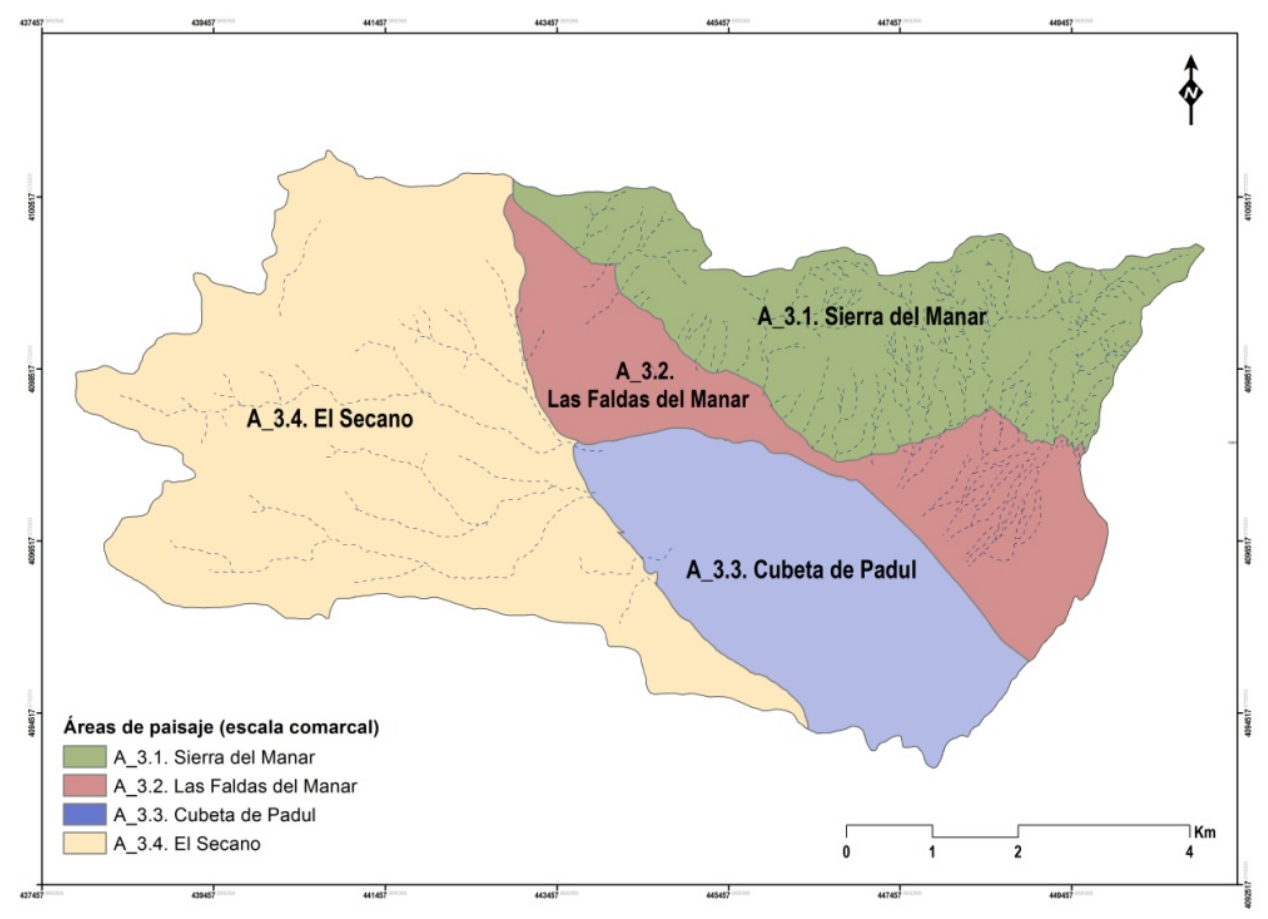

Fuente: elaboración propia

Posteriormente, a escala comarcal o supralocal (Nivel 3. Escala $\approx 1 / 50000-1 / 25000$ ) se identificaron cuatro Tipos de paisaje (T_3.1. Sierras calizo-dolomíticas meso y supramediterráneas de uso forestal e industrial; T_3.2. Piedemontes conglomeráticos mesomediterráneos de uso agrícola y urbano-industrial; T_3.3. Depresión tectónica endorreica mesomediterránea con humedales y uso agrícola y urbano-industrial; y T_3.4. Cerros y lomas mesomediterráneas de borde de cuenca con matorral serial y uso agrícola). Siguiendo con este proceso iterativo, a esta misma escala se identificaron cuatro Áreas paisajísticas coincidentes con unidades topográficas 
menores con identidad propia: A_3.1. Sierra del Manar; A_3.2. Las Faldas del Manar; A_3.3. Cubeta de Padul; y A_3.4. El Secano (Figura 7). A este nivel, elementos como el relieve, bioclima, y los usos y aprovechamientos antrópicos se utilizan para la clasificación y denominación de los Tipos paisajísticos; por su parte, para la denominación de las Áreas se recurre a la toponimia utilizada por la población comarcal con la finalidad de fortalecer la identidad paisajística.

Figura 8. Mapa de Tipos de paisaje (escala local). Cuenca endorreica de Padul

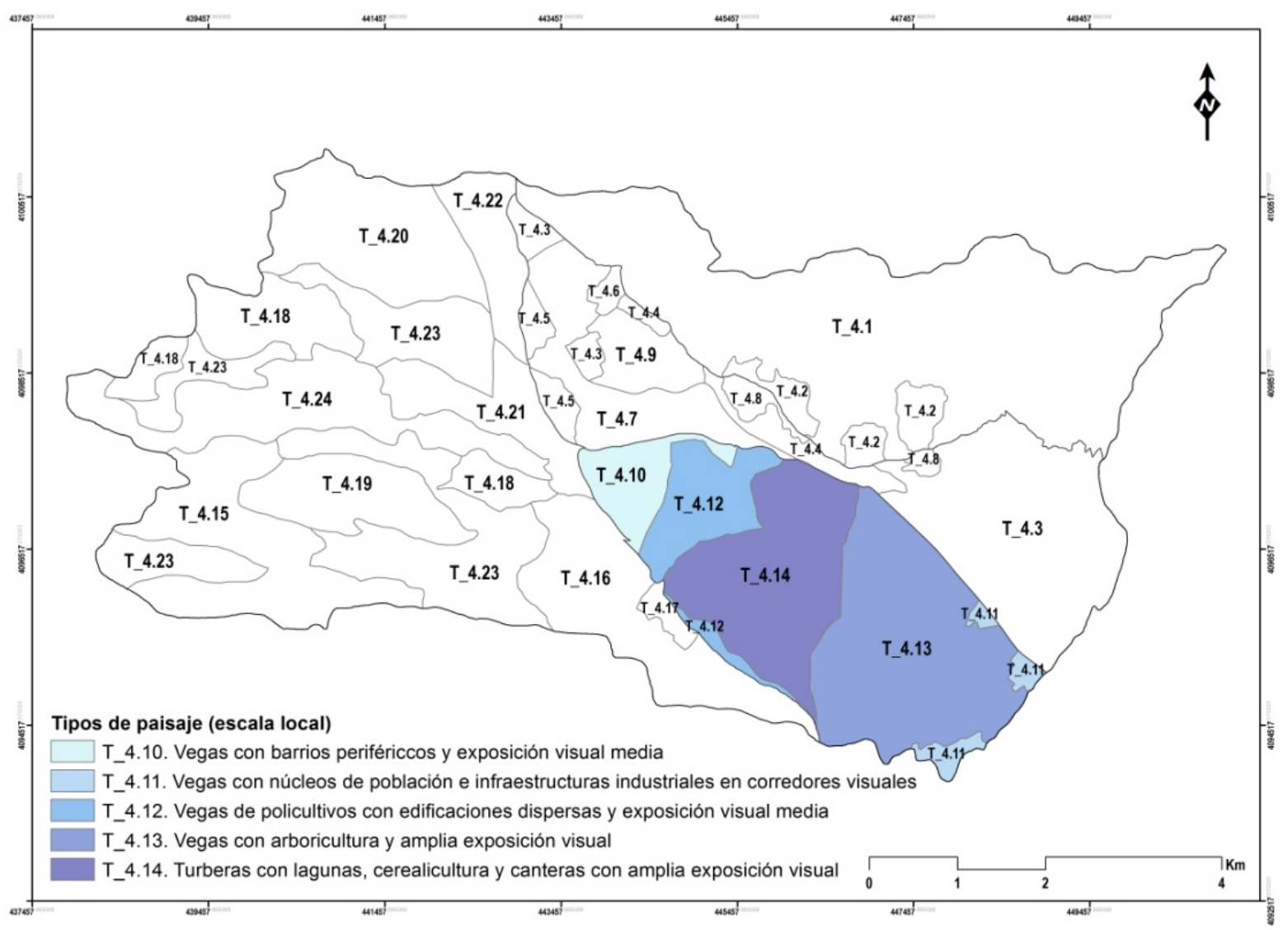

Fuente: elaboración propia

Considerando el último nivel de la zonificación, a escala local (Nivel 4. Escala $\approx 1 / 10.000$ 1/5.000) la clasificación de los paisajes adquirió una gran diversidad propia de las escalas de detalle. Se identificaron 24 Tipos y 75 Áreas de paisaje. Los Tipos paisajísticos reconocidos en este último nivel de la jerarquía presentan una extensión reducida y proceden de la combinación de atributos formales y funcionales de distinta naturaleza. Elementos como la topografía (altitud, pendiente), litología, fisiografía, bioclima, vegetación o edafología, junto con referencias a los usos y aprovechamientos del suelo se utilizaron para su denominación. Considerando el detalle que ofrece esta escala, se incorporó también la alusión al componente visual o escénico. Por su parte, para la clasificación y denominación de las Áreas se recurrió a la terminología popular utilizada por la población local. En este sentido, si tomamos como ejemplo el Área "A_3.3. Cubeta de Padul" (Figura 7), al ejecutar el proceso iterativo de clasificación del paisaje en Tipos y Áreas se produjo 
una desagregación de dicha Área en cinco Tipos de paisaje a escala local: T_4.10, T_4.11, T_4.12, T_4.13 y T_4.14 (Figura 8). Siguiendo este proceso iterativo, si tomamos ahora como ejemplo el Tipo "T_4.14. Turberas con lagunas, cerealicultura y canteras con amplia exposición visual", éste se desagregó en tres Áreas de paisaje: A_4.14.1, A_4.14.2 y A_4.14.3 (Figura 9), cuya denominación responde a la terminología popular utilizada por la población local.

Si consideramos como paisaje de referencia (a escala local) el Área A_4.14.3. Turbera y Laguna del Aguadero (véase su localización en Figura 9), su zonificación paisajística e integración multiescalar a distintos niveles puede representarse a partir de la Pirámide Taxonómica de Paisaje (PTP) -Landscape Taxonomic Pyramid, LTP- propuesta por Gómez-Zotano et al. (2018) que, de forma gráfica, permite comprender las posibilidades que ofrece el paisaje y su integración multiescalar (Figura 10).

Figura 9. Mapa de Áreas de paisaje (escala local). Cuenca endorreica de Padul

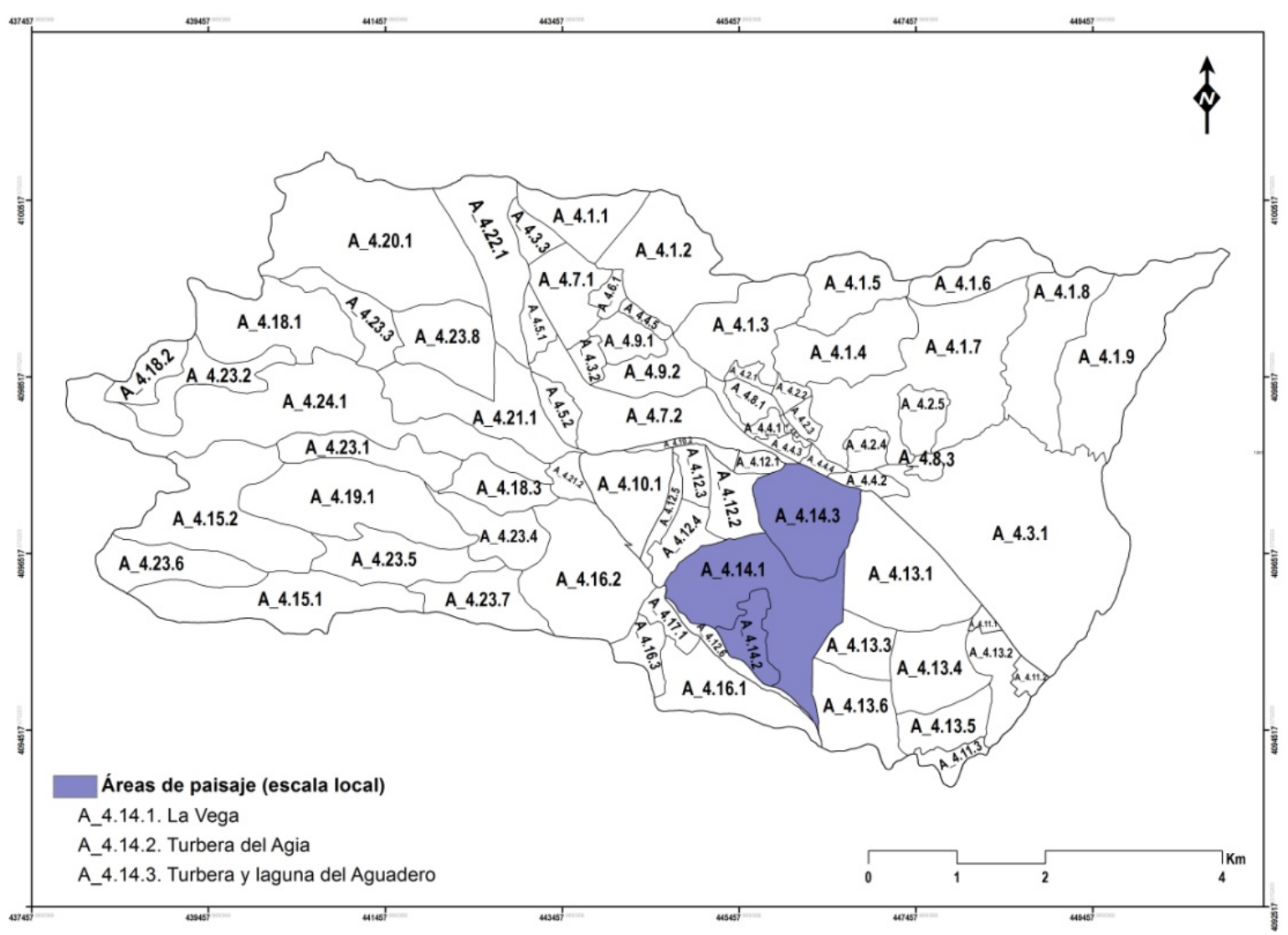

Fuente: elaboración propia 
Figura 10. Ejemplo de zonificación del paisaje e integración multiescalar a partir de la Pirámide Taxonómica de Paisaje para el Área A_4.14.3 Turbera y Laguna del Aguadero

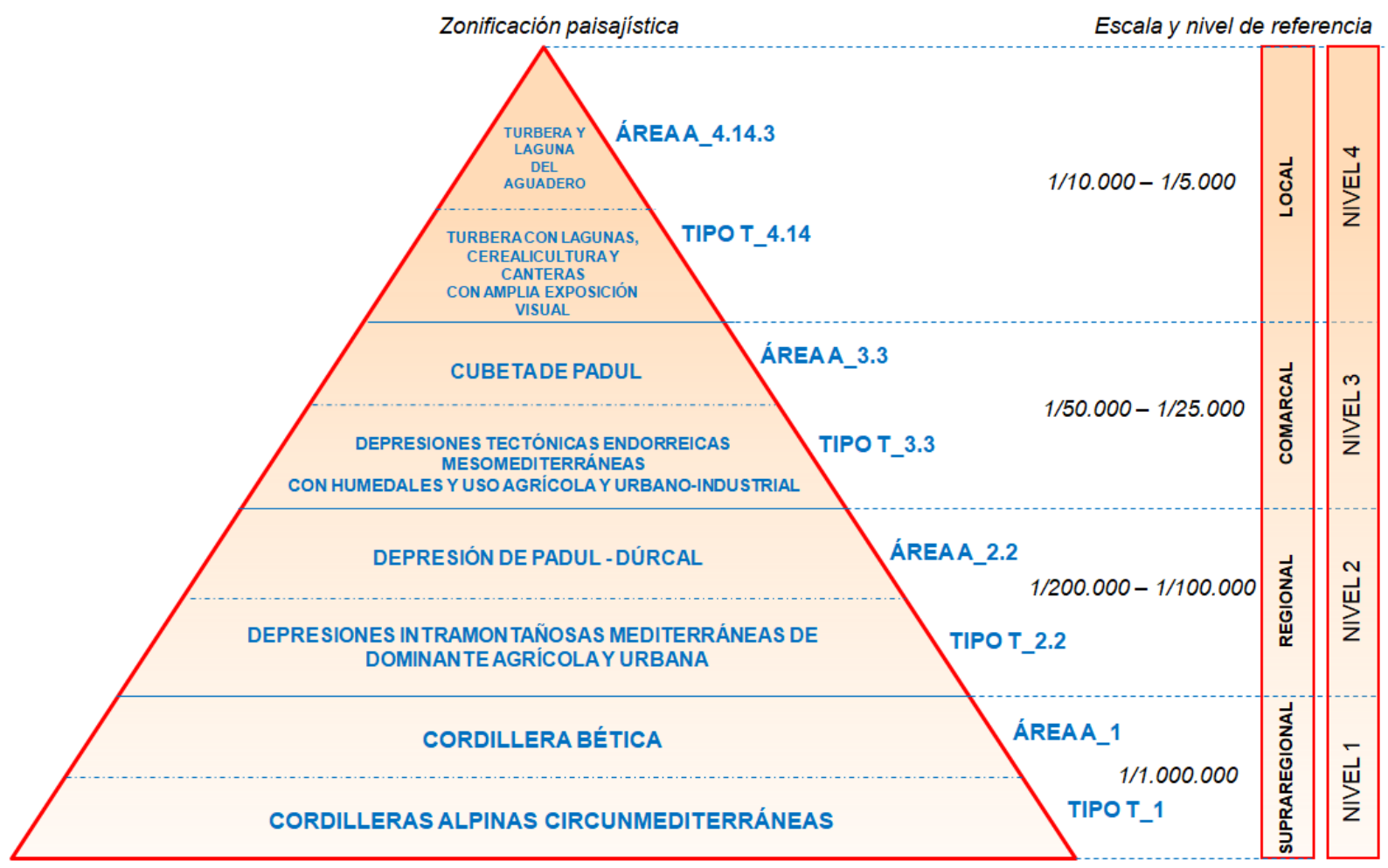

Fuente: elaboración propia a partir de la propuesta LTP de Gómez-Zołano et al. (2018)

Atendiendo a la metodología propuesta, la última fase de esta primera etapa (fase 8) consistió en la caracterización de los Tipos y Áreas previamente identificados. El establecimiento del carácter se definió a partir de la combinación particular y reconocible de los elementos y procesos que definen a un determinado Tipo y/o Área de paisaje, con especial incidencia en sus características clave (particularidades en relación al subsistema abiótico, biótico, dinámica y evolución reciente, presiones y riesgos, así como aspectos escénico-visuales) y que, por tanto, le otorgan un carácter propio o diferencial. Tomando como ejemplo el Área A_4.14.3. Turbera y Laguna del Aguadero (Nivel 4. Escala local; véase su localización en Figura 9), su carácter paisajístico podría sintetizarse de la siguiente forma:

Esta Área de paisaje se localiza en el sector centro-septentrional de la fosa tectónica de Padul a una altitud media de 725 m.s.n.m. Alberga la superficie de carrizal más extensa de toda la cuenca junto a una reciente laguna de agua dulce que ocupa la superficie de una cantera de turba clausurada en 2010 y que llega a alcanzar los 10 m de profundidad.

Desde el punto de vista litológico predominan depósitos de turba intercalados con arenas, arcillas, gravas y yesos, asociados a una depresión tectónica con control 
estructural [...]. El clima mediterráneo continentalizado seco junto con la topografía y litología ha dado lugar a la configuración de una escorrentía superficial espasmódica, debiéndose el hidroperíodo permanente de la laguna a los aportes subterráneos [...]. Su evolución histórica presenta numerosas particularidades o características propias que la convierten en un Área única en el contexto de la cuenca. Los principales factores de cambio tienen lugar a finales del S.XVIII. El año 1779 constituye un momento crucial para esta Área, pues tuvo lugar el gran proyecto de desecación de la laguna. Intereses agrarios y motivos de insalubridad justificaron la ejecución del proyecto. Éste consistió en la creación de un complejo entramado de canales de desagüe o "madres" en torno a un canal principal (Madre Maestra). Este conjunto de canales, de 9 Km de longitud, provocaron la desecación de la turbera casi en su totalidad [...]. La puesta en cultivo de la superficie desecada no solo desencadenó la conformación de un sistema de drenaje que persiste en la actualidad y que puede concebirse como un elemento patrimonial de primer orden, sino que progresivamente se eliminó el bosque galería y la vegetación lacustre-palustre hasta conformar una extensa vega en regadío que presenta una amplia exposición visual [...]. (Figura 11).

Figura 11. Fotografías del Área A_4.14.3. Turbera y Laguna del Aguadero (2017)
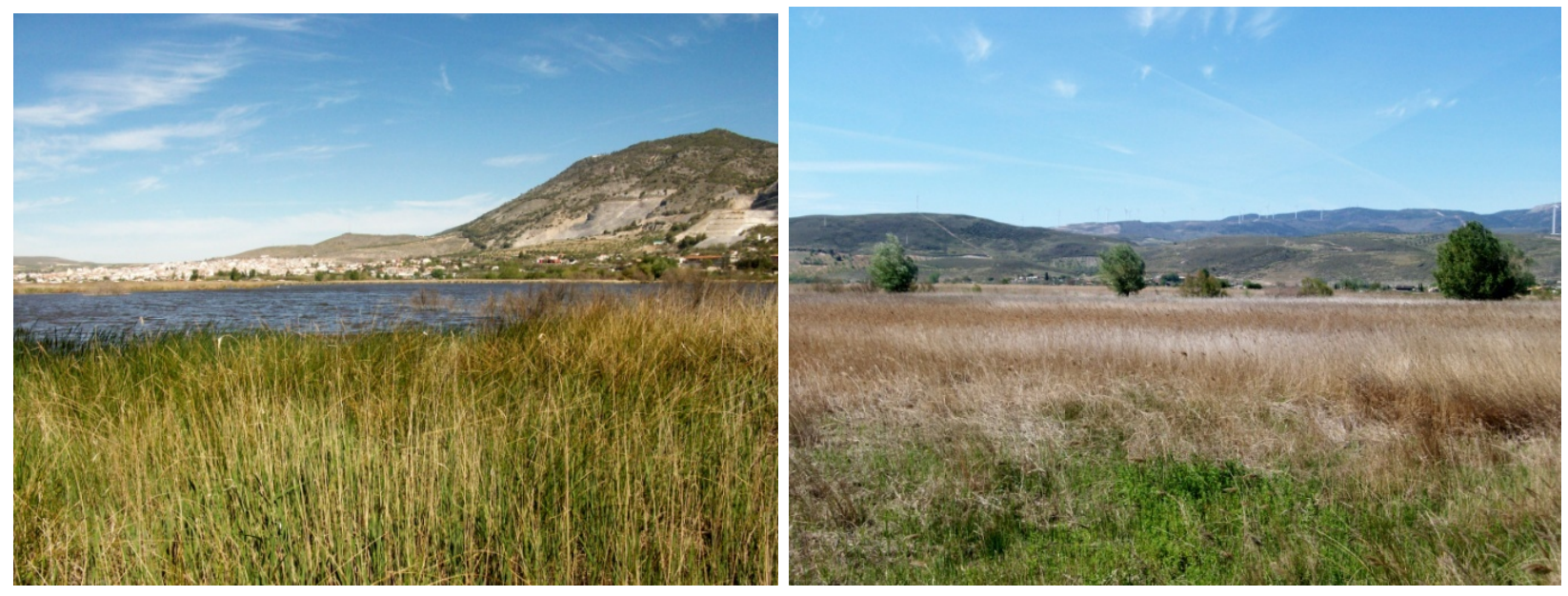

Fuente: elaboración propia

\subsection{Etapa 2: Valoración y propuestas}

Esta segunda etapa consistió en la cualificación (valoración) y establecimiento de objetivos de calidad paisajística de los Tipos y Áreas de paisaje previamente identificados y caracterizados.

Se consideraron prioritarios los Tipos y Áreas paisajísticas a escala comarcal (Nivel 3) y local (Nivel 4), especialmente los Tipos y Áreas paisajísticas coincidentes con los humedales, cuyos paisajes son más dinámicos, frágiles y vulnerables. En este sentido, y a modo de ensayo metodológico, las 
últimas fases del método (fases 9, 10 y 11) se implementaron en el Área A_4.14.3. Turbera y Laguna del Aguadero (Nivel 4, escala local).

La cualificación del Área A_4.14.3 se estableció a partir de la identificación y descripción de los valores naturales, productivos, histórico-patrimoniales, de uso social, mitológicos, simbólicos y estéticos del paisaje (Tabla 5). De acuerdo con las Orientaciones del CEP (2008), estos sistemas de valores pertenecen tanto a la cultura erudita como a la cultura popular, son cualitativos y no cuantificables y algunos de ellos son algunas veces mutuamente opuestos.

Tabla 5. Valores paisajísticos del Área A_4.14.3. Turbera y Laguna del Aguadero

\section{Valores Ecológicos / Naturales}

- Especificidad hidro-edáfica: esta área paisajística alberga el humedal de tipo turbera más meridional del continente europeo.

- Humedal con hidroperíodo permanente-fluctuante en el contexto mediterráneo del SE peninsular (lámina de agua permanente).

- Alta productividad biológica (vegetal y faunística): esta área se caracteriza por albergar uno de los carrizales más extensos del sur peninsular y más de 170 especies de aves cuyos movimientos migratorios inciden en la fenología visual y sonora del paisaje.

- Conservación parcial de la cubierta vegetal autóctona (carrizal-espadañal y bosque galería), que incide en la configuración de un paisaje semi-natural.

\section{Valores y recursos productivos}

- Históricos: la explotación de los recursos vegetales en esta área ha estado ligada a dos actividades: por una parte, la ganadería, que utilizaba las superficies de pastizal como alimento; por otra, la recolección de anea y carrizo para la fabricación de cestas, trenzados, esteras y chozas.

- Actuales: las limitaciones derivadas de la protección ambiental de esta área han supuesto una simplificación de la explotación de los recursos; en cambio, ha generado la aparición de nuevos valores. La agricultura constituye en la actualidad el principal valor productivo de las superficies aledañas a la laguna del Aguadero. La fertilidad edáfica (suelos de turba) junto con el abastecimiento de agua mediante acequias y brazales, le confieren a esta turbera una clara vocación agrícola. Esta agricultura se caracteriza por un monocultivo de cereal en el que se intercalan pequeñas parcelas con policultivos tradicionales de subsistencia (huerta) y algunos olivares de reducida extensión. Por su parte, la ganadería supone en la actualidad una actividad residual; tan solo algunos rebaños de ganado ovino utilizan esta área como zona de pasto. 


\section{Valores histórico-patrimoniales}

- Canales de desagüe (madres): su origen se remonta a finales del S.XVIII y constituyen una de las principales señas de identidad de esta área paisajística.

- Infraestructuras hidráulicas de origen medieval en las superficies cultivadas aledañas al humedal (acequias y brazales).

- Parcelario y minifundismo histórico: de la desecación histórica del humedal y su puesta en cultivo se deriva también la tipología del parcelario, que se remonta igualmente a finales del S.XVIII. Tras la desecación del humedal, su único propietario (Conde de Villamena de Cozvíjar) fragmentó la superficie desecada en pequeñas parcelas para su cultivo, explotándolas bajo régimen de colonato. La tipología parcelaria se mantiene en la actualidad.

- Patrimonio industrial: de la explotación de la turba mediante una cantera a cielo abierto entre 19562010 se deriva un legado patrimonial-industrial que forma parte de los elementos constitutivos de esta área (maquinaria, tendidos eléctricos, señalizaciones, etc.) y contribuye a su singularidad paisajística.

- Patrimonio paleontológico: esta área coincide con un yacimiento paleontológico de primer orden. En ésta se hallaron los restos de mandíbulas, fémures y defensas de mamut lanudo (Mammuthus primigenius) en 1982-1983.

\section{Valores de uso social}

- Facilidad de acceso a esta área de paisaje por su localización entre dos vías de comunicación de primer orden (Carretera Nacional CN-323 y Autovía A-44). Especialmente significativa es la CN323, que constituye el límite del área y supone un corredor de gran consumo visual.

- Frecuencia de visita elevada: 1500 visitantes/año según datos aportados por Excmo. Ayuntamiento de Padul y Aula de Naturaleza El Aguadero.

- Infraestructuras de uso público que permiten el acceso al paisaje: esta área cuenta con 5 observatorios de aves, 2 áreas recreativas (incluyendo un parque infantil) y un sendero señalizado (Ruta del Mamut).

- Desarrollo de actividades educativas y de formación, especialmente relacionadas con talleres de anillamiento científico de aves.

\section{Valores mitológicos y simbólicos}

- Sobre uno de los manantiales que alimentan el humedal en esta área (Ojo Oscuro) recaen numerosas leyendas como la "Leyenda de José Lao y su yunta de bueyes".

- Presencia de elementos mitológicos como la "Higuera de los Deseos".

- Simbología relacionada con la megafauna del pasado: del hallazgo de los restos paleontológicos de mamut lanudo se ha derivado que este animal se convierta en el símbolo del humedal. Cabe destacar la denominación del sendero que permite el acceso al humedal (Sendero del Mamut) así como una recreación del animal a tamaño real junto al Centro de Interpretación del Mamut, inserto en esta área de paisaje. 


\section{Valores estéticos}

\begin{tabular}{|c|c|}
\hline $\begin{array}{l}\text { Elementos / } \\
\text { procesos que } \\
\text { contribuyen a la } \\
\text { calidad estética } \\
\text { del paisaje }\end{array}$ & $\begin{array}{l}\text { - Fenofases estacionales: durante el período otoño-invernal predominan los } \\
\text { tonos dorados en el extenso carrizal y los rojizos en las hojas secas del bosque } \\
\text { galería. Por el contrario, durante la primavera y el verano, el color verde } \\
\text { intenso domina el área. En este caso, al verdor del carrizal y bosque de ribera } \\
\text { se suma el de los brotes de las semillas de cereal en las parcelas agrícolas } \\
\text { circundantes, que se tiñen de tonalidades ocres conforme se acerca la } \\
\text { cosecha. } \\
\text { - Frecuentes nieblas que con cierta periodicidad diaria se producen en esta área } \\
\text { y le confieren un halo de misterio muy característico. } \\
\text { - Considerando el fondo escénico del área, destaca Sierra Nevada como uno } \\
\text { de sus principales valores estéticos. Sus cumbres nevadas durante el invierno y } \\
\text { primavera, así como su intensa tonalidad grisácea durante el estío, diversifican } \\
\text { la gama cromática del fondo escénico del humedal. } \\
\text { - Contraste cromático y textural entre la masa de agua (Laguna del Aguadero) y } \\
\text { la vegetación y cultivos circundantes. }\end{array}$ \\
\hline & Valores estéticos \\
\hline $\begin{array}{l}\text { Elementos / } \\
\text { procesos que } \\
\text { reducen la } \\
\text { calidad estética } \\
\text { del paisaje }\end{array}$ & $\begin{array}{l}\text { Elementos / procesos intrínsecos al área de paisaje: } \\
\text { - Presencia de edificaciones de carácter rural que adoptan la función de } \\
\text { segunda residencia. Suelen aparecer delimitadas por un vallado que impide el } \\
\text { acceso al paisaje. Cuando además se incorporan elementos arbóreos } \\
\text { ornamentales, se conforma una pantalla visual que reduce notoriamente la } \\
\text { visibilidad del humedal. } \\
\text { Elementos / procesos extrínsecos al área de paisaje: } \\
\text { - Edificaciones industriales y comerciales, viviendas de segunda residencia y } \\
\text { casas de aperos. La distribución de estos elementos no se rige por un patrón } \\
\text { de distribución concreto, lo que origina un paisaje caótico que, por su amplia } \\
\text { exposición visual, reduce el valor estético del área. Además, por su extensa } \\
\text { distribución en el piedemonte serrano, las canteras de áridos contribuyen aún } \\
\text { más a reducir la calidad del fondo escénico de la Turbera y Laguna del } \\
\text { Aguadero. }\end{array}$ \\
\hline
\end{tabular}

Fuente: elaboración propia

Para llevar a cabo la sistematización de los valores de esta Área se consideraron prioritarios aquellos posibles elementos y/o procesos con incidencia paisajística que presentan un valor real o potencial en esta Área. Éstos fueron previamente identificados en fases metodológicas precedentes (análisis de los fundamentos naturales, históricos y culturales del paisaje). No obstante, cabe destacar que las Orientaciones del CEP plantean el interés que puede conllevar la inclusión de la participación pública en la cualificación y/o valoración del paisaje. Sin embargo, y debido a las múltiples opciones existentes al respecto (encuesta pública, reuniones informativas, exposiciones pedagógicas, etc.) y la especificidad que supone insertar la participación social en materia de 
paisaje, ésta se ha concebido como una futura línea de investigación que permita aportar nuevos procedimientos y/o mejoras en la presente propuesta metodológica.

Para el establecimiento de objetivos de calidad paisajística o recomendaciones se consideró la Estrategia de Paisaje de Andalucía (EPA) como instrumento de referencia. Siguiendo con el ensayo metodológico en el Área A_4.14.3. Turbera y Laguna del Aguadero, los objetivos de la EPA directamente aplicables a dicha Área se correspondieron con los objetivos 1: "Impulsar la recuperación y mejora paisajística del patrimonio natural" y, concretamente, su línea estratégica 12 (Curso fluviales, humedales e infraestructuras hidráulicas) y 7:"Potenciar la sensibilización, educación y la formación en materia de paisaje".

Atendiendo a la EPA, el Plan Andaluz de Humedales (PAH, 2002) constituiría el instrumento de planificación de referencia. No obstante, ésta manifiesta que, además de los objetivos y actuaciones derivados del PAH, con un enfoque eminentemente ecosistémico, debe incorporarse también la dimensión paisajística.

En este sentido, y partir del PAH, en primer lugar se llevó a cabo a modo de diagnóstico una sistematización de las funciones, bienes, servicios y principales alternaciones del humedal incluido en el Área A_4.14.3. Se incorporaron también aquellos aspectos relacionados con la dimensión del paisaje, especialmente las alteraciones con incidencia directa e indirecta en la configuración y calidad paisajística del área (Tabla 6). 
Tabla 6. Funciones, bienes, servicios y principales alteraciones del Área A_4.14.3. Turbera y Laguna del Aguadero

\begin{tabular}{|c|c|c|}
\hline FUNCIONES & BIENES & SERVICIOS \\
\hline Descarga y recarga de acuíferos & $\begin{array}{l}\text { Disponibilidad de agua para la } \\
\text { agricultura }\end{array}$ & Almacenamiento de agua \\
\hline $\begin{array}{l}\text { Mantenimiento de la humedad } \\
\text { ambiental }\end{array}$ & $\begin{array}{l}\text { Banco de información } \\
\text { palinológica y paleoclimática } \\
\text { (depósitos de turba) }\end{array}$ & Asimilación de contaminantes \\
\hline $\begin{array}{l}\text { Retardo de flujos superficiales de } \\
\text { agua }\end{array}$ & $\begin{array}{l}\text { Bienes culturales (sistema } \\
\text { histórico de explotación de la } \\
\text { turba, leyendas, valores } \\
\text { simbólicos y espirituales, valores } \\
\text { estéticos y emocionales) }\end{array}$ & Control de inundación \\
\hline $\begin{array}{l}\text { Hábitat de poblaciones y } \\
\text { comunidades faunísticas } \\
\text { singulares }\end{array}$ & $\begin{array}{l}\text { Espacio para el ocio, recreo y } \\
\text { turismo } \\
\text { (Infraestructuras de uso público) }\end{array}$ & $\begin{array}{l}\text { Control de erosión y } \\
\text { retención de sedimentos }\end{array}$ \\
\hline Soporte de cadenas tróficas & $\begin{array}{l}\text { Espacio de interés didáctico y } \\
\text { científico (hidrológico, botánico, } \\
\text { faunístico, paisajístico) }\end{array}$ & Control microclimático \\
\hline $\begin{array}{l}\text { Eslabones básicos de las rutas } \\
\text { migratorias de las aves }\end{array}$ & $\begin{array}{l}\text { Diversidad paisajística en el } \\
\text { contexto de su cuenca asociada }\end{array}$ & Fertilidad del suelo \\
\hline $\begin{array}{l}\text { Preservación de restos } \\
\text { arqueológicos y paleontológicos }\end{array}$ & $\begin{array}{l}\text { Elevada productividad biológica } \\
\text { (vegetación, fauna) }\end{array}$ & $\begin{array}{l}\text { Sumidero y/o fuente de } \\
\text { nutrientes }\end{array}$ \\
\hline \multicolumn{3}{|c|}{ PRINCIPALES RIESGOS Y ALTERACIONES CON INCIDENCIA EN EL HUMEDAL } \\
\hline Alteraciones en la cubeta & \multicolumn{2}{|c|}{$\begin{array}{l}\text { Desecación histórica (canales de drenaje) } \\
\text { Excavaciones derivadas de la extracción de turba (canteras) } \\
\text { Proliferación de edificaciones } \\
\text { Líneas eléctricas }\end{array}$} \\
\hline $\begin{array}{l}\text { Alteraciones en el régimen } \\
\text { hidrológico e hidroperíodo }\end{array}$ & \multicolumn{2}{|c|}{$\begin{array}{l}\text { Modificaciones de la red hidrográfica } \\
\text { - canalizaciones internas en el humedal (canales de } \\
\text { drenaje) } \\
\text { - canalizaciones externas con incidencia en el humedal } \\
\text { (canalización de la rambla en el núcleo urbano de } \\
\text { Padul, que conecta directamente con la laguna) } \\
\text { - destrucción de cursos superficiales en áreas inmediatas } \\
\text { con incidencia en la escorrentía superficial y subterránea } \\
\text { (canteras de áridos) }\end{array}$} \\
\hline $\begin{array}{l}\text { Alteraciones en la calidad de las } \\
\text { aguas }\end{array}$ & \multicolumn{2}{|c|}{$\begin{array}{l}\text { Residuos sólidos urbanos } \\
\text { Residuos líquidos procedentes de la depuradora municipal } \\
\text { Residuos líquidos procedentes de la agricultura }\end{array}$} \\
\hline $\begin{array}{l}\text { Alteraciones en la estructura de } \\
\text { las comunidades biológicas }\end{array}$ & \multicolumn{2}{|c|}{$\begin{array}{l}\text { Introducción de especies vegetales y animales exóticos (cangrejo } \\
\text { rojo americano, carpa, galápago de Florida, etc.). } \\
\text { Presión turístico-recreativa (ocasional) } \\
\text { Contaminación acústica (barrenados de las canteras y tránsito de } \\
\text { vehículos pesados en CN-323) } \\
\text { Construcción de nuevas edificaciones }\end{array}$} \\
\hline
\end{tabular}

Fuente: elaboración propia 
Dado que el PAH se centra fundamentalmente en el humedal como ecosistema, para el establecimiento de objetivos de calidad se consideró también el Mapa de Presiones y Riesgos elaborado en la fase 4, detectándose que las directrices de actuación paisajística deberían fundamentarse en torno a 5 líneas prioritarias (Tabla 7):

Tabla 7. Posibles Líneas de actuación y Objetivos de calidad para el Área A_4.14.3. Turbera y Laguna del Aguadero

\begin{tabular}{|c|c|}
\hline Línea de actuación (L) & Objetivos (0) \\
\hline $\begin{array}{l}\text { L1. Construcción de } \\
\text { nuevas edificaciones e } \\
\text { infraestructuras }\end{array}$ & $\begin{array}{l}\text { O1.1. Limitar la construcción de nuevas edificaciones y, en caso de construirse, } \\
\text { que éstas respeten la tipología constructiva local y su localización no suponga } \\
\text { un obstáculo visual al humedal. En este sentido, puede incorporarse la } \\
\text { visibilidad del emplazamiento de las nuevas construcciones como elemento } \\
\text { proyectual (posición relativa a los principales puntos de observación o } \\
\text { proximidad de itinerarios concurridos), evitando modelos de implantación } \\
\text { dispersos que desconfiguren el carácter paisajístico del área. Las edificaciones } \\
\text { deberían optar por volúmenes simples y proporciones equilibradas, } \\
\text { minimizando el uso de materiales que desvaloricen el paisaje por su color, } \\
\text { brillo o naturaleza. Por su parte, los vallados y cercados que contienen } \\
\text { elementos arbóreos ornamentales que impiden la visibilidad del humedal } \\
\text { podrían optar por una vegetación arbustiva y arbórea con especies autóctonas } \\
\text { de porte columnar y distancias de plantación cortas; también se deberían evitar } \\
\text { podas geométricas que le confieren un carácter artificial a las alineaciones. } \\
\text { O1.2. Minimizar la apertura de nuevos accesos y adaptar el trazado de los ya } \\
\text { existentes a peatones y vehículos. Se estima conveniente la utilización de } \\
\text { recursos vegetales para su acondicionamiento, minimizar la pavimentación y, } \\
\text { en su caso, optar por materiales permeables que impidan la compactación del } \\
\text { suelo. }\end{array}$ \\
\hline $\begin{array}{l}\text { L2. Explotaciones de uso } \\
\text { agrícola }\end{array}$ & $\begin{array}{l}\text { O2.1. Incrementar el control de los productos fitosanitarios utilizados en la } \\
\text { agricultura que puedan contaminar las aguas superficiales y subterráneas, así } \\
\text { como incidir en los procesos de eutrofización. Se ha de incrementar también la } \\
\text { vigilancia sobre posibles vertidos a los canales de drenaje, que adquieren el } \\
\text { carácter de biotopo o espacio vital para la flora y fauna; así como en toda la } \\
\text { superficie ocupada por el humedal. } \\
\text { O2.2. Controlar los vallados ilegales del parcelario, que además de } \\
\text { impermeabilizar el acceso al paisaje y reducir su calidad, constituyen un riesgo } \\
\text { para la fauna que accede al interior de la parcela, pues carecen de trampillas } \\
\text { para el escape de los animales. }\end{array}$ \\
\hline $\begin{array}{l}\text { L3. Visibilidad y } \\
\text { acondicionamiento visual }\end{array}$ & $\begin{array}{l}\text { O3.1. Implantar una pantalla visual entre el humedal, la CN-323 y las canteras } \\
\text { de áridos, que constituyen un impacto de primer orden desde cualquier punto } \\
\text { de observación del área objeto de estudio. En este sentido, las alineaciones } \\
\text { arboladas densas con especies autóctonas de bosque galería podrían suponer } \\
\text { una solución útil. }\end{array}$ \\
\hline
\end{tabular}




\begin{tabular}{|c|c|}
\hline $\begin{array}{l}\text { L4. Revalorización de } \\
\text { elementos patrimoniales }\end{array}$ & $\begin{array}{l}\text { O4.1. Potenciar la cultura en torno al sistema hídrico del humedal y su entorno, } \\
\text { tanto de la red hídrica natural (arroyos y laguna) como de las infraestructuras } \\
\text { de origen antrópico (canales de desagüe, infraestructuras industriales asociadas } \\
\text { a la explotación de turba), pues constituyen un elemento singular y valioso en la } \\
\text { configuración histórica del paisaje. } \\
\text { O4.2. Promocionar mediante, por ejemplo, paneles de interpretación } \\
\text { paisajística, la historia de la explotación secular y desecación de la laguna, y en } \\
\text { consecuencia, los esfuerzos de gestión y conservación que se están llevando a } \\
\text { cabo en la actualidad; así como el tratamiento de sus relaciones funcionales y } \\
\text { simbólicas. }\end{array}$ \\
\hline $\begin{array}{l}\text { L5. Agentes públicos e } \\
\text { implicación en la gestión } \\
\text { del paisaje }\end{array}$ & $\begin{array}{l}\text { O5.1. Reforzar la colaboración entre los agentes públicos (administración local } \\
\text { y regional, Parque Natural de Sierra Nevada) y el sector privado con la } \\
\text { finalidad de implementar el uso racional establecido por el Convenio Ramsar. } \\
\text { O5.2. Integrar el uso racional del humedal en políticas sectoriales a distintos } \\
\text { niveles de planificación (local, regional, estatal) con la finalidad de mejorar la } \\
\text { ordenación territorial y paisajística del humedal y su cuenca asociada. } \\
\text { O5.3. Promover la gestión integrada del humedal en el contexto de su cuenca } \\
\text { y no como elemento aislado tal y como establece el PAH. } \\
\text { O5.4. Perfeccionar las campañas de información y sensibilización con la } \\
\text { finalidad de promocionar el valor de los humedales, que supera la perspectiva } \\
\text { faunística y alcanza la eco-cultural y paisajística. } \\
\text { O5.5. Adquisición por parte de la administración de las propiedades privadas } \\
\text { ocupadas por carrizal y canteras de turba para poder llevar a cabo una } \\
\text { restauración integral del humedal, sin menoscabo de su patrimonio industrial } \\
\text { asociado. } \\
\text { O5.6. Controlar la roturación de las tierras circundantes a la masa de agua, } \\
\text { pues se trata de suelos que mantienen una notable humedad edáfica y } \\
\text { funcionan como criptohumedales que contribuyen a la diversificación } \\
\text { paisajística. } \\
\text { O5.7. Evitar la recreación, es decir, la reproducción de escenarios visuales } \\
\text { emblemáticos que se aproximan más a los objetivos de los parques temáticos } \\
\text { que a la restauración ecosistémica del humedal así como de su carácter } \\
\text { paisajístico, tal y como establece el PAH. }\end{array}$ \\
\hline
\end{tabular}

Fuente: elaboración propia

Finalmente, y en relación con la fase 11 (Seguimiento y establecimiento de indicadores), el CEP sugiere el establecimiento de herramientas para el seguimiento de las transformaciones paisajísticas y la eficacia de las políticas que se adopten. En este sentido, se propone un modelo de ficha de seguimiento que permita valorar la dinámica del Área paisajística A_4.14.3 (Turbera y Laguna del Aguadero), atendiendo a los elementos y procesos del paisaje previamente analizados y, especialmente, considerando la evolución o tendencia de su carácter paisajístico (Tabla 8). 
Tabla 8. Propuesta de ficha de seguimiento para el Área de paisaje A_4.14.3. Turbera y Laguna del Aguadero

\begin{tabular}{|c|c|c|c|}
\hline \multicolumn{2}{|c|}{ VARIABLES } & \multirow{2}{*}{\multicolumn{2}{|c|}{$\begin{array}{c}\text { INDICADORES / PARÁMETROS A EVALUAR } \\
\text { Calidad del agua superficial (parámetros físico-químicos) }\end{array}$}} \\
\hline \multirow{12}{*}{$\begin{array}{l}\text { FUNDAMENTOS } \\
\text { NATURALES }\end{array}$} & \multirow{5}{*}{$\begin{array}{l}\text { Hidrología / } \\
\text { Geomorfología }\end{array}$} & & \\
\hline & & $\begin{array}{l}\text { Calidad del agua subterránea } \\
\text { piezométricos) }\end{array}$ & (parámetros físico-químicos, niveles \\
\hline & & Modificación y/o alteración o & e los cursos de escorrentía superficial \\
\hline & & Nivel de inundación de la cul & \\
\hline & & Modificaciones y/o alteracior & es de la cubeta lacustre-palustre \\
\hline & \multirow{3}{*}{ Vegetación natural } & \multirow{2}{*}{$\begin{array}{l}\text { Grado de cobertura vegetal } \\
(\%)\end{array}$} & Estado \\
\hline & & & Dinámica o tendencia \\
\hline & & \multicolumn{2}{|c|}{ Tipo de vegetación (especies, áreas de distribución) } \\
\hline & \multirow{4}{*}{ Hábitat faunístico } & \multicolumn{2}{|c|}{ Abundancia y diversidad de especies (censos, inventarios...) } \\
\hline & & \multicolumn{2}{|l|}{ Nuevas especies detectadas } \\
\hline & & \multicolumn{2}{|l|}{ Pérdida de especies } \\
\hline & & \multicolumn{2}{|l|}{$\mathrm{N}^{\circ}$ de parejas reproductoras } \\
\hline \multirow{9}{*}{$\begin{array}{l}\text { USOS DEL SUELO, } \\
\text { EXPLOTACIÓN } \\
\text { ANTRÓPICA Y } \\
\text { ELEMENTOS } \\
\text { CULTURALES }\end{array}$} & \multirow{4}{*}{ Tipo de uso } & \multirow{2}{*}{ Uso A (\%) } & Estado \\
\hline & & & Dinámica / Tendencia \\
\hline & & \multirow{2}{*}{ Uso B (\%)... } & Estado \\
\hline & & & Dinámica / Tendencia \\
\hline & \multirow{2}{*}{$\begin{array}{l}\text { Elementos } \\
\text { patrimoniales y } \\
\text { culturales }\end{array}$} & Elemento A & $\begin{array}{l}\text { Conservado / Rehabilitado / } \\
\text { En deterioro progresivo }\end{array}$ \\
\hline & & Elemento B... & $\begin{array}{l}\text { Conservado / Rehabilitado / } \\
\text { En deterioro progresivo }\end{array}$ \\
\hline & $\begin{array}{l}\text { Introducción de } \\
\text { nuevos elementos } \\
\text { físicos } \\
\text { (edificaciones, } \\
\text { infraestructuras, } \\
\text { etc.) }\end{array}$ & \multicolumn{2}{|c|}{ Compatibles / Incompatibles / Impacto Severo } \\
\hline & \multirow{2}{*}{$\begin{array}{l}\text { Uso público del } \\
\text { humedal }\end{array}$} & \multicolumn{2}{|c|}{$\begin{array}{l}N^{\circ} \text { de visitantes y motivo de la visita (libre, actividad programada, } \\
\text { etc.) }\end{array}$} \\
\hline & & \multicolumn{2}{|c|}{ Estado de las infraestructuras de uso público } \\
\hline \multirow{2}{*}{\multicolumn{2}{|c|}{ ESTRUCTURA VISUAL Y ESCÉNICA }} & \multicolumn{2}{|l|}{ No modificada } \\
\hline & & \multicolumn{2}{|c|}{$\begin{array}{l}\text { Modificada: elementos visuales compatibles, incompatibles, } \\
\text { elementos con impacto severo, etc. }\end{array}$} \\
\hline \multirow{4}{*}{\multicolumn{2}{|c|}{$\begin{array}{l}\text { ESTIMACIÓN DEL CARÁCTER } \\
\text { PAISAJIISTICO }\end{array}$}} & \multicolumn{2}{|l|}{ Estable o sin cambios } \\
\hline & & \multicolumn{2}{|l|}{ Cambios leves (indicar) } \\
\hline & & \multicolumn{2}{|l|}{ Cambios severos (indicar) } \\
\hline & & \multicolumn{2}{|l|}{ Nuevo carácter (describir) } \\
\hline
\end{tabular}

Fuente: elaboración propia 


\section{Discusión y conclusiones}

La metodología propuesta, fundamentada en el procedimiento LCA, se configura como una metodología útil para la clasificación y caracterización de los paisajes a diferentes escalas espaciales. La universalidad de la metodología queda demostrada, así mismo, tras su aplicación exitosa en otros ámbitos geográficos de muy diversa naturaleza (Brabyn, 2009; Butler \& Åkerskog, 2014; Riesco Chueca et al., 2014; Muñoz Guerrero \& Gómez Zotano, 2016). Permite además su adaptación al Convenio Europeo del Paisaje y cumplir con las etapas propuestas por éste respecto a los procesos que conducen a la acción paisajística (identificación, caracterización y cualificación).

Esta metodología ha permitido establecer una perspectiva transversal en el análisis paisajístico, introduciendo criterios biofísicos, históricos, culturales, perceptivo-visuales y propositivos (líneas de actuación y objetivos). Se supera así una delimitación en unidades de paisaje con una finalidad únicamente descriptiva, pues la secuencia metodológica propuesta permite que los Tipos y Áreas de paisaje sean operativos así como la posible inclusión de la participación pública en la denominación de las áreas de paisaje, procesos de valoración, propuesta de objetivos de calidad, etc. Se trata así de una metodología sistémica, que comprende las estructuras territoriales que se derivan del doble entramado del subsistema natural y sociocultural; genética, pues tiene como objetivo conocer cómo se ha llegado a la situación actual de cualquier territorio; interescalar, pues permite adecuarse a diferentes escalas territoriales; e iterativa, ya que expresa una acción que se compone de acciones - o clasificaciones- repetidas: Áreas y Tipos de paisaje.

Para llevar a cabo la clasificación del paisaje, y de acuerdo con la metodología LCA, se han definido una serie de Tipos paisajísticos que manifiestan un mismo carácter o combinación de características. Posteriormente, los Tipos se han subdividido en Áreas de paisaje, fragmentando, individualizando y regularizando los Tipos. Este proceso ha permitido una articulación iterativa en Tipos y Áreas basada en el reconocimiento de su carácter que al mismo tiempo alterna el principio de concreción localizadora: cada Área es un lugar con un nombre reconocible por la población y cada Tipo es un conjunto de rasgos de carácter que se manifiesta en distintos lugares (tipificación abstracta). No obstante, la justificación de las variables utilizadas para la delimitación de Tipos y Áreas ha requerido la consideración de la extensión del ámbito de estudio y la escala de trabajo. En este sentido, estudios precedentes (James \& Gittins, 2007; Lipský \& Romportl, 2007; Gómez Zotano \& Riesco Chueca, 2010) corroboran que el procedimiento LCA adquiere su pleno potencial cuando se llega a una descripción fina, plenamente compatible con un trabajo de campo detallado. Por tanto, considerando la adaptación a diferentes escalas territoriales que permite la metodología LCA, la clasificación del paisaje alcanza su máxima expresión a escala local, comarcal y regional. A escalas superiores, ciertas propiedades del paisaje dejan de ser perceptibles o relevantes y dificultan su gestión. En este sentido, trabajos previos como los de Forman (1995), Schermann \& 
Baudry (2002), Bartlett et al. (2017) y Trop (2017) han corroborado la estrecha relación existente entre la escala de análisis y su ajuste metodológico; una cuestión compleja que el método LCA ha resuelto para el análisis del paisaje mediante su propuesta de clasificación en Tipos y Áreas, que permite, de forma iterativa, su integración a distintas escalas.

A partir de los resultados obtenidos se constata que para la planificación, gestión y ordenación del paisaje la escala local resulta idónea, especialmente para la gestión del humedal, pues su sistema de explotación, presiones y riesgos se producen de forma muy localizada. La complejidad de la realidad territorial alcanza aquí su máxima expresión, sin menoscabo de la perspectiva general del entorno circundante (máxime en los espacios endorreicos donde la dinámica ambiental y paisajística del sistema-lacustre es interdependiente de su cuenca asociada).

Las conclusiones que se derivan de la propuesta metodológica y su aplicación son las siguientes:

- El método desarrollado permite la implementación del CEP al cumplir las etapas propuestas por éste respecto a los procesos que conducen a la acción paisajística: conocimiento de los paisajes (identificación, caracterización), formulación de objetivos de calidad paisajística y seguimiento de las transformaciones.

- El procedimiento metodológico LCA ha permitido desarrollar en el ámbito de estudio seleccionado: (a) Un ejercicio descriptivo-analítico de los fundamentos naturales del paisaje; procesos históricos y fundamentos socioeconómicos; características escénicas y visuales; (b) Un ejercicio de diagnóstico, atendiendo a la transformación de las bases naturales del paisaje (unidades ecogeográficas originales), sus procesos y dinámicas históricas, así como su incidencia en la configuración actual del paisaje; (c) Un ejercicio propositivo que contempla la valoración del paisaje y sus posibilidades de actuación (posibles líneas de actuación y objetivos de calidad).

- La metodología propuesta presenta cuestiones de interés como la delimitación del paisaje en Tipos y Áreas de manera iterativa y la aplicabilidad a diferentes escalas espaciales. Esta flexibilidad ha permitido la identificación de los paisajes de la cuenca objeto de estudio y su integración en contextos territoriales más amplios.

- De acuerdo con las Orientaciones del CEP y a partir de la metodología experimentada, se concluye que la planificación territorial ha de asumir que los trabajos de caracterización y valoración del paisaje constituyen un proceso previo a la concreción de acciones y determinaciones dirigidas a su protección, gestión y ordenación. No obstante, sin una dimensión propositiva, la aportación del paisaje a la planificación territorial quedaría limitada a un acercamiento estrictamente descriptivo, ajeno al carácter dinámico del paisaje.

- La propuesta metodológica ha de considerarse en todo caso como una adaptación del método LCA para la implementación del Convenio Europeo del Paisaje en los ámbitos territoriales 
asociados a cuencas endorreicas. Constituye por tanto una guía indicativa abierta a nuevas actualizaciones y/o adaptaciones a las necesidades de gestión territorial y a los recursos de estos espacios existentes en cada lugar.

Por su parte, las conclusiones que se derivan del ámbito de estudio son las siguientes:

- Se ha detectado que las acciones que se han llevado a cabo en la cuenca objeto de estudio en general, y sus humedales en particular, no han sido suficientes para su protección, gestión y ordenación. Esta cuestión está relacionada con que ésta comprende un territorio cuyos límites naturales son independientes a las delimitaciones político-administrativas. En este sentido, la consideración en los estudios de paisaje de ámbitos que no se ajustan necesariamente a límites administrativos los hacen especialmente útiles para la definición de acciones paisajísticas de carácter supramunicipal. Por su parte, en el caso específico de los humedales, se precisa su inserción en la planificación territorial del conjunto de la cuenca y no únicamente una gestión o protección aislada, tal y como se ha hecho hasta ahora.

- A diferencia de otro tipo de paisajes, por sus características orográficas, la cuenca adquiere en gran medida un carácter de cuenca visual autocontenida, lo que incrementa considerablemente su fragilidad visual.

- Los humedales y sus cuencas asociadas no han sido objeto preferente desde un punto de vista paisajístico, presentando un interés generalizado desde el punto de vista ecosistémico. Con la implementación del método propuesto se ha contribuido a superar esta perspectiva sesgada, pues se ofrece un análisis holístico donde se interrelacionan los procesos naturales, sociales, culturales y perceptuales.

- La explotación secular de los humedales (elementos articuladores de su cuenca asociada) ha contribuido a configurar las características actuales de los paisajes del conjunto de la cuenca, contribuyendo además a la identidad de la misma. En consecuencia, deben ser objeto de atención preferente, pues constituyen paisajes con numerosos especificidades naturales y culturales imbricadas, lo que incrementa su fragilidad.

Declaración responsable: El autor declara que no existe ningún conflicto de interés en relación con la publicación de este artículo. 


\section{Bibliografía}

Aldred, O., \& Fairclough, G. (2003). Historic Landscape Characterization: taking stock of the method. London: English Heritage/Somerset County Council.

Arias-García, J., \& Gómez-Zotano, J. (2015). La planificación y gestión de los humedales de Andalucía en el marco del Convenio Ramsar. Investigaciones Geográficas, 63, 117-129. http://dx.doi.org/10.14198/INGEO2015.63.08

Arias García, J. (2016). Identificación, caracterización y cualificación de los paisajes de las grandes cuencas endorreicas de Andalucía: ensayo metodológico para la implementación del Convenio Europeo del Paisaje en sistemas lacustre-palustres. Tesis doctoral. Universidad de Granada. Retrieved from http://digibug.ugr.es/handle/10481/40944

Arias-García, J., Gómez-Zotano, J., \& Delgado-Peña, J.J. (2017). Classifying landscape in endorheic basins: A methodological approach for the implementation of the European Landscape Convention. European Journal of Geography, 8(2), 55-77.

Bartlett, D., Gómez-Martín, E., Milliken, S., \& Parmer, D. (2017): Introducing landscape character assessment and the ecosystem service approach to India: A case study. Landscape and Urban Planning, 167, 257-266. http://dx.doi.org/10.1016/j.landurbplan.2017.06.013

Belovsky, G.E., Stephens, D., Perschon, C., Birdsey, P., Paul, D., Naftz, D., Baskin, R., ... Allen, D.V. (2011). The Great Salt Lake Ecosystem (Utah, USA): Long term data and a structural equation approach. Ecosphere, 2(3), 1-40. http://dx.doi.org/10.1890/ES10-00091.1

Bertrand, G. (1968). Paysage et géographie physique globale. Esquisse méthodologique. Revue géographique des Pyrénées et du Sud-Ouest. Sud-Ouest Européen, 39(3), 249-272.

Bertrand, G. (1974). Essai sur la systématique du paysage: les Montagnes Cantabriques Centrales (Nord-Ouest de l'Espagne). (Doctoral dissertation, Université de Toulouse Le Mirail, France).

Bertrand, G. (1978). Le paysage entre la nature et la société. Revue Géographique des Pyrenées et du Sud-Ouest, 49(2), 239-258.

Brabyn, L. (2009). Classifying Landscape Character. Landscape Research, 34(3), 299-321. http://dx.doi.org/10.1080/01426390802371202

Butler, A., \& Åkerskog, A. (2014). Awareness-raising of landscape in practice. An analysis of Landscape Character Assessments in England. Land Use Policy, 36, 441-449. http://dx.doi.org/10.1016/j.landusepol.2013.09.020

Canedo, C., Pillco Zolá, R., \& Berndtsson, R. (2016). Role of hydrological studies for the development of the TDPS system. Water, 8(4). http://dx.doi.org/10.3390/w8040144 
Consejería de Medio Ambiente (2002). Plan Andaluz de Humedales. Sevilla: Consejería de Medio Ambiente, Junta de Andalucía.

Consejo de Europa (2000). Convenio Europeo del Paisaje: Florencia, 20 de octubre de 2000 (versión española). Ministerio de Asuntos Exteriores. Retrieved from http://www.culturaydeporte.gob.es/cultura-mecd/dms/mecd/cultura-mecd/areascultura/patrimonio/Convenio_europeo_paisaje.pdf

Consejo de Europa (2008). Recomendación CM/Rec(2008)3 del Comité de Ministros a los Estados miembro sobre las orientaciones para la aplicación del Convenio Europeo del Paisaje. Retrieved from https://publicacionesoficiales. boe.es/detail.php?id=010355108-0001

Delclaux, F., Coudrain, A., \& Condom, T. (2007). Evaporation estimation on Lake Titicaca: A synthesis review and modelling. Hydrological Processes, 21(13), 1664-1677. https://doi.org/10.1002/hyp.6360

Dumont, H.J. (1998). The Caspian Lake: History, biota, structure, and function. Limnology and Oceanography, 43(1), 44-52. https://doi.org/10.4319/lo.1998.43.1.0044

Elmore, A.J., Kaste, J.M., Okin, G.S., \& Fantle, M.S. (2008). Groundwater influences on atmospheric dust generation in deserts. Journal of Arid Environments, 72(10), 1753-1765. https://doi.org/10.1016/j.jaridenv.2008.05.008

Fairclough, G., Sarlöv Herlin, I., \& Swanwick, C. (2018). Landscape character approaches in global, disciplinary and policy context: an introduction. In G. Fairclough, I. Sarlöv Herlin, I., \& C. Swanwick (Eds.), Routledge Handbook of Landscape Character Assessment. Current Approaches to Characterisation and Assessment (pp. 3-20). Routledge: Abingdon, Oxon; New York, NY.

Forman, T.T. (1995). Some general principles of landscape and regional ecology. Landscape Ecology, 10(3), 133-142.

Gómez Zotano, J., \& Riesco Chueca, P. (Coord.) (2010). Marco conceptual y metodológico para los paisajes españoles. Aplicación a tres escalas espaciales. Sevilla: Centro de Estudios Paisaje y Territorio. Consejería de Obras Públicas y Transportes, Junta de Andalucía.

Gómez-Zotano, J., Riesco-Chueca, P., Frolova, M., \& Rodríguez-Rodríguez, J. (2018). The landscape taxonomic pyramid (LTP): a multiscale classification adapted to spatial planning. Landscape Research. https://doi.org/10.1080/01426397.2017.1404021

Habeck-Fardy, A., \& Nanson, G.C. (2014). Environmental character and history of the Lake Eyre Basin, one seventh of the Australian continent. Earth-Science Reviews, 132, 39-66. https://doi.org/10.1016/j.earscirev.2014.02.003 
Hostetler, S.W. (1995). Hydrological and Thermal Response of Lakes to Climate: Description and Modeling. Berlin/Heidelberg, Germany: Springer.

Huybers, K., Rupper, S., \& Roe, G.H. (2016). Response of closed basin lakes to interannual climate variability. Climate Dynamics, 46(11-12), 3709-3723. https://doi.org/10.1007/s00382$\underline{015-2798-4}$

James, P., \& Gittins, J.W. (2007). Local Landscape Character Assessment: An Evaluation of Community-led Schemes in Cheshire. Landscape Research, 32(4), 423-442. https://doi.org/10.1080/01426390701449794

Jensen, L. H. (2005). Changing conceptualization of landscape in English landscape assessment methods. In B. Tress, G. Tress, G. Fry \& P. Opdam (Eds.), From Landscape Research to Landscape Planning: Aspects of Integration, Education, and Application (pp. 161-171). Wageningen UR Frontis Series. Springer: Dordrecht, Berlin, Heidelberg.

Joly, F. (2006). Les eaux sauvages des régions arides. Notions de base sur l'hydrologie des déserts. Géomorphologie: relief, processus, environnement, 4, 285-298. Retrieved from http://journals.openedition.org/geomorphologie/93

Junta de Andalucía (2012, March 1). Estrategia de Paisaje de Andalucía. Retrieved from http://www.juntadeandalucia.es/medioambiente/portal_web/web/temas_ambientales/evaluacion _integracion_planificacion/planificacion_ambiental/estrategias/estrategia_paisaje/Estrategia_de_Pai saje de Andalucia_2012.pdf

Laity, J. (2008). Deserts and deserts environments. United Kingdom: Wiley-Blackwell Publications, Chichester.

Lambrick, G., Hind, J., \& Wain, I. (2013). Historic Landscape Characterisation in Ireland: best practice guidance. Ireland: The Heritage Council of Ireland Series.

Lemly, A.D., Kingsford, R.T., \& Thompson, J.R. (2000). Irrigated agriculture and wildlife conservation: conflict on a global scale. Environmental Management, 25, 485-512. https://doi.org/10.1007/s002679910039

Lemoalle, J., Bader, J-C., Leblanc, M., \& Sedick, A. (2012). Recent changes in Lake Chad: Observations, simulations and management options (1973-2011). Global and Planetary Change, 80-81, 247-254. https://doi.org/10.1016/j.gloplacha.2011.07.004

Li, G., \& Zhang, B. (2017). Identification of landscape character types for trans-regional integration in the Wuling Mountain multi-ethnic area of southwest China. Landscape and Urban Planning, 162, 25-35. https://doi.org/10.1016/j.landurbplan.2017.01.008 
Lipský, D., \& Romportl, Z. (2007). Classification and tipology of cultural landscapes: methods and apllications. In K. Ostaszewska, I. Szumacher, S. Kulczyk, \& E. Malinowska (Eds.), The Role of Landscape Studies for Sustainable Development (pp. 519-535). Poland: University of Warsaw.

Lowenthal, D. (1978). Flinding valued landscapes. Progress in Human Geography, 2(3), 373-418. Mata Olmo, R. (2008). El paisaje, patrimonio y recurso para el desarrollo territorial sostenible; conocimiento y acción pública. Arbor: Ciencia, Pensamiento y Cultura, CLXXXIV(729), 155-172. https://doi.org/10.3989/arbor.2008.i729.168

Mata Olmo, R., \& Sanz Herráiz, C. (Dir.) (2004). Atlas de los Paisajes de España. Madrid: Ministerio de Medio Ambiente.

Moreira, J.M., Rodríguez, M., Móniz, C., Ojeda, J.F., Rodríguez, J., Venegas, C., \& Zoido, F. (2005). Mapa de los paisajes de Andalucía. In COPT y CMA: Atlas de Andalucía. Vol. II. Cartografía ambiental. Sevilla: Consejería de Obras Públicas y Transportes, Consejería de Medio Ambiente.

Morgan, M. (1978). Perspectives on landscape aesthetics. Progress in Human Geography, 2(3), $527-532$.

Muñoz Guerrero, D.A., \& Gómez Zotano, J. (2016). Propuesta metodológica para la gestión de los paisajes de páramo en el marco de la Iniciativa Latinoamericana del Paisaje (LALI). Perspectiva Geográfica, 21(2), 37-62. Retrieved from

http://revistas.uptc.edu.co/index.php/perspectiva/article/view/5850

Riesco Chueca, P., Alcántara Manzanares, J., Cáceres Clavero, F., Díaz Iglesias, J.M., Ghislanzoni, M., Gómez Zotano, J., Guerrero Álvarez, J.J., ... Zoido Naranjo, F. (2014). Bases para la realización del Sistema Compartido de Información sobre el Paisaje de Andalucía (SCIPA). Aplicación a Sierra Morena. Sevilla: Consejería de Medio Ambiente y Ordenación del Territorio, Junta de Andalucía.

Sánchez del Árbol, M.A. (2009). El medio bio-físico de la Depresión de Padul (Valle Alto de Lecrín). In J. Gómez Zotano \& F. Ortega Alba (Coord.), El sector central de las Béticas: una visión desde la Geografía Física (pp. 299-332). Granada: Editorial Universidad de Granada.

Schermann, N., \& Baudry, J. (2002). Analyse descriptive multi-échelle de la structure d'un Paysage. Revue internationale de géomatique, 12(3-4), 1-18. https://doi.org/10.3166/rig. 12.169-186

Stabbetorp, O. E., Sollund, M. L. B., Brendalsmo, J., \& Norderhaug, A. (2007). Layers of the past: a theory and method for historical landscape analysis. Landscape Research, 32(4), 463-479. https://doi.org/10.1080/01426390701449844 
Swanwick, C. (2002). Landscape Character Assessment. Guidance for England and Scotland. Edinburgh: The Countryside Agency; Scottish Natural Heritage.

Swanwick, C. (2004). The assessment of countryside and landscape character in England: an overwiew. In K. Bishop \& A. Philips (Eds.), Countryside Planning (pp. 102-124). London: Earthscan.

Trop, T. (2017). From knowledge to action: Bridging the gaps toward effective incorporation of Landscape Character Assessment approach in land-use planning and management in Israel. Landscape Use Policy, 61, 220-230. https://doi.org/10.1016/j.landusepol.2016.10.052

Varis, O., \& Kummu, M. (2012). The Major Central Asian River Basins: An Assessment of Vulnerability. International Journal of Water Resources Development, 28(3), 433-452. https://doi.org/10.1080/07900627.2012.684309

Villegas Molina, F. (1967). Laguna de Padul. Evolución Geológico-Histórica. Estudios Geográficos, 28(109), 561-576.

Wiens, J.A., \& Milne, B.T. (1989). Scaling of 'landscapes' in landscape ecology, or, landscape ecology from a beetle's perspective. Landscape Ecology, 3(2), 87-96.

Wu, J. (2006). Landscape Ecology, Cross-disciplinarity, and Sustainability Science. Landscape Ecology, 21(1), 1-4. https://doi.org/10.1007/s10980-006-7195-2

Wurtsbaugh, W.A., Miller, C., E Null, S., Justin DeRose, R., Wilcock, P., Hahnenberger, M., Howe, F., \& Moore, J. (2017). Decline of the world's saline lakes. Nature Geoscience, 10(11), 816-821. http://dx.doi.org/10.1038/ngeo3052

Yapiyev, V., Sagintayev, Z., Inglezakis, V. J., Samarkhanov, K., \& Verhoef, A. (2017). Essentials of endorheic basins and lakes: a review in the context of current and future water resource management and mitigation activities in Central Asia. Water, 9(10), 798. https://doi.org/10.3390/w9100798

Zoido Naranjo, F., \& Jiménez Olivencia, Y. (Dir.) (2015). Catálogo de paisajes de la provincia de Granada. Sevilla: Centro de Estudios Paisaje y Territorio. Consejería de Medio Ambiente y Ordenación del Territorio.

Zube, E.H., Sell, J.L., \& Taylor, J.G. (1982). Landscape perception: Research, application and theory. Landscape Planning, 9(1), 1-33. https://doi.org/10.1016/0304-3924(82)90009-0 